OPEN ACCESS

Edited by:

Paola Italiani,

Italian National Research Council

(CNR), Italy

Reviewed by:

James Harris,

Monash University, Australia Sian M. Henson,

Queen Mary University of London, United Kingdom

*Correspondence:

Peisong Gao pgao1@jhmi.edu

Specialty section:

This article was submitted to Inflammation,

a section of the journal

Frontiers in Immunology

Received: 07 August 2019 Accepted: 13 November 2019 Published: 29 November 2019

Citation:

Sachdeva K, Do DC, Zhang Y, HuX,

Chen J and Gao P (2019)

Environmental Exposures and Asthma

Development: Autophagy, Mitophagy,

and Cellular Senescence.

Front. Immunol. 10:2787.

doi: 10.3389/fimmu.2019.02787

\section{Environmental Exposures and Asthma Development: Autophagy, Mitophagy, and Cellular Senescence}

\author{
Karan Sachdeva ${ }^{1}$, Danh C. Do ${ }^{1}$, Yan Zhang ${ }^{1,2}$, Xinyue Hu ${ }^{1,2}$, Jingsi Chen ${ }^{1,3}$ and \\ Peisong Gao ${ }^{1 *}$ \\ 1 Johns Hopkins Asthma \& Allergy Center, Johns Hopkins University School of Medicine, Baltimore, MD, United States, \\ ${ }^{2}$ Department of Respiratory Medicine, Xiangya Hospital, Central South University, Changsha, China, ${ }^{3}$ Department of \\ Dermatology, Children's Hospital, Chongqing Medical University, Chongqing, China
}

Environmental pollutants and allergens induce oxidative stress and mitochondrial dysfunction, leading to key features of allergic asthma. Dysregulations in autophagy, mitophagy, and cellular senescence have been associated with environmental pollutant and allergen-induced oxidative stress, mitochondrial dysfunction, secretion of multiple inflammatory proteins, and subsequently development of asthma. Particularly, particulate matter $2.5\left(\mathrm{PM}_{2.5}\right)$ has been reported to induce autophagy in the bronchial epithelial cells through activation of AMP-activated protein kinase (AMPK), drive mitophagy through activating PTEN-induced kinase 1(PINK1)/Parkin pathway, and induce cell cycle arrest and senescence. Intriguingly, allergens, including ovalbumin (OVA), Alternaria alternata, and cockroach allergen, have also been shown to induce autophagy through activation of different signaling pathways. Additionally, mitochondrial dysfunction can induce cell senescence due to excessive ROS production, which affects airway diseases. Although autophagy and senescence share similar properties, recent studies suggest that autophagy can either accelerate the development of senescence or prevent senescence. Thus, in this review, we evaluated the literature regarding the basic cellular processes, including autophagy, mitophagy, and cellular senescence, explored their molecular mechanisms in the regulation of the initiation and downstream signaling. Especially, we highlighted their involvement in environmental pollutant/allergen-induced major phenotypic changes of asthma such as airway inflammation and remodeling and reviewed novel and critical research areas for future studies. Ultimately, understanding the regulatory mechanisms of autophagy, mitophagy, and cellular senescence may allow for the development of new therapeutic targets for asthma.

Keywords: oxidative stress, autophagy, mitophagy, senescence, asthma

\section{INTRODUCTION}

Asthma is a leading serious chronic illness of children and adults worldwide, and its prevalence has been increasing over the past few decades $(1,2)$. Million people worldwide are affected, including 24 million in the United States (3). Asthma is chronic airway inflammation characterized by airway hyper-responsiveness, wheezing, cough, and dyspnea, and has become a major contributing factor to missed time from school and work, and is also a major cause of hospitalization and 
emergency department visits. It is well-recognized that the increase in asthma prevalence may be mainly attributed to industrialization- and urbanization-generated environmental pollutants (4-10). In China, a study of over 30,000 adults showed that the prevalence of persistent cough, sputum production, and wheezing was associated with major traffic roads, factories, and large smokestacks (11). This was supported by another crosssectional study of 23,326 Chinese children, which showed that the prevalence of asthma was higher for those residing near areas with serious air pollution (12). Diesel exhaust particles (DEPs) are of particular concern and contributed to more than $90 \%$ of the particulate matters (PMs) derived from traffic sources in European and American cities (13). Particulate matter 2.5 $\left(\mathrm{PM}_{2.5}\right)$, one of the major pollutants in urban areas, accounts for a large proportion of the atmospheric particulate matter and increased prevalence and symptom severity in children and adult patients with asthma (14-16) and other respiratory diseases $(17,18) . \mathrm{PM}_{2.5}$ as a mixture of various chemical constituents has been shown to promote oxidative stress and inflammation (19). Furthermore, concentrated transition metals in the environment have been shown to stimulate the production of reactive oxygen species (ROS) 19, leading to airway injury and inflammation (20).

In addition to environmental pollutants, it is well-known that environmental allergens are also major players in the development of allergic sensitization and asthma. Importantly, recent studies made novel findings that environmental pollutants co-exposure with allergens can lead to increased allergic sensitization and severe asthma (21-23). Particularly, prenatal exposure to DEPs is associated with an increased risk of allergic sensitization, early childhood wheeze, and asthma (24, 25). Of interest, co-exposure to DEP and house dust mite (HDM) can promote allergic sensitization and induce major features of a more severe asthma $(9,26-29)$. Furthermore, we have recently shown that benzo(a)pyrene $(\mathrm{BaP})$ co-exposure with dermatophagoides group 1 (Der $\mathrm{f} 1$ ) can activate aryl hydrocarbon receptor (AhR) signaling, which regulates ROS generation and TSLP and IL-33 expression (30). Similarly, a very recent study demonstrated that PM2.5 disturbs the balance of Th17/Treg cells by impairing differentiation of $\mathrm{T}_{\text {reg }}$ cells and promoting differentiation of Th17 cells through the molecular pathways AhR-HIF-1 $\alpha$ (hypoxia-inducible factor1alpha) and AhR-Got1 (glutamate oxaloacetate transaminase 1) in a cockroach allergen-induced mouse model of asthma (31). Warren et al. reported that acute inhalant exposure to an agriculture acquired organic dust extract (ODE) impacts lung inflammatory responses in a murine model of experimental allergic asthma, suggesting that allergic asthma may prime

Abbreviations: CRE, Cockroach extract; HDM, House dust mite; $\mathrm{PM}_{2.5}$, Particulate matter 2.5; SASP, Senescence-associated secretory phenotype; ROS, Reactive oxygen species; NAC, N-Acetyl Cysteine; AMPK, AMP-activated protein kinase; PINK1, PTEN-induced kinase; PI3K, Phosphatidylinositol4,5-bisphosphate 3-kinases; mTOR, Mechanistic target of rapamycin; ATG, Autophagy-related gene; CaMKII, Calmodulin-dependent protein kinase II; CQ, Chloroquine; BAL, Bronchoalveolar lavage; AHR, Airway hyperresponsiveness; COPD, Chronic obstructive pulmonary disease; IPF, Idiopathic pulmonary fibrosis; 3-MA, 3-Methyladenine. the lung microenvironment response toward an exaggerated response following exposure to a dusty farm environment (32). Thus, future studies are warranted to identify the underlying mechanisms regarding the co-exposure-induced exacerbation of allergic asthma. In this review, we evaluated the literature regarding the basic cellular processes, including autophagy, mitophagy, and cellular senescence, and discussed their involvement in environmental pollutant/allergen-induced major features of asthma and biological regulation. Additionally, we identified areas of unmet research needed and their potentials as novel therapeutic avenues for the treatment of asthma and allergic diseases.

\section{AUTOPHAGY}

It has been postulated that dysregulation of basic cellular processes which maintain homeostasis and physiological balance may lead to the key clinical features of asthma. Autophagy, a homeostatic process with multiple effects on immunity, has been shown to play important roles in causing downstream changes initiated by environmental pollutants, allergens, and respiratory tract infections (33-40). Autophagy is a mechanism in which the eukaryotic cell encapsulates damaged proteins or organelles for lysosomal degradation and recycling (41). The autophagic pathway has recently been suggested to be involved in the several key features of asthma pathogenesis, including eosinophilic airway inflammation (42), airway hyper-responsiveness (36), and airway remodeling (43). It has been shown that $\mathrm{PM}_{2.5}$ exposure can induce cell autophagy and airway inflammation through different immunological and molecular mechanisms (44-46). Furthermore, exposure to allergens has also been shown to activate autophagy, as demonstrated in studies with cockroach allergen (47), Alternaria extract (48), and caffeine (49).

Autophagy is a process that has been maintained over ages of evolution, and by which damaged and misfolded proteins along with aged or damaged organelles are transported to lysosomes for elimination and digestion (50). Currently, three major types of autophagy are recognized: macroautophagy, microautophagy, and chaperone-mediated autophagy (51). Of these, macroautophagy is the most extensively studied, which uses autophagosomes, double-membraned vesicles, to engulf cytoplasmic proteins and organelles for delivery to the lysosome for degradation. Autophagosomes fusing with lysosomes are termed autophagolysosomes (52). After fusion with lysosomes, the cargo delivered is degraded by lysosomal enzymes and then transported to the cytoplasm (53-55). The byproducts of lysosomal degradation (e.g., amino acids) are recycled and then used for protein synthesis that enables salvage of energy normally used in de novo synthesis. Microautophagy as a second type of autophagy does not require autophagosomes but involves the direct engulfment of the cargo that may include proteins and lipids by the invagination of the lysosomal membrane (56). Chaperone-mediated autophagy (CMA) as a third type of autophagy is unique to mammalian cells (57). CMA is a highly regulated cellular process that involves the degradation of a selective subset of cytosolic proteins in lysosomes. In contrast 
to macroautophagy that engulfs and delivers predominantly larger structures for bulk degradation of cargo, CMA delivers individual proteins for lysosomal degradation. CMA involves a co-chaperone complex led by heat shock cognate 70 (HSC70) that recognizes target proteins that have a KFERQ-like pentapeptide sequence (52). Chaperone-bound proteins are transported to lysosomes, in which they are recognized by the lysosomeassociated membrane protein type $2 \mathrm{a}$ (LAMP2a) receptor, a major regulator of CMA. LAMP2a is a transmembrane protein component that oligomerizes and forms a translocon complex for internalization and degradation of chaperonedelivered cargo in the lysosome (58). In this review, we mainly focused on macroautophagy, the form of autophagy dealing with the destruction and recycling of damaged macromolecules and organelle structures, and highlighted the significance of macroautophagy in the maintenance of cellular energetic balance and homeostasis.

\section{REGULATION OF AUTOPHAGY}

Significant progress has been made in understanding the molecular mechanisms of autophagy and the regulation of autophagy in the past 10 years (59). These studies, together with discoveries of the autophagy-related (ATG) genes and their associations with specific diseases $(60,61)$, provide a multidimensional perspective of mechanisms by which ATG gene-dependent autophagy pathways are critical in the pathogenesis of human diseases. The autophagy pathway is usually described as involving a set of 16-20 core conserved ATG genes. These core proteins are involved in regulating initiation of autophagy by the UNC51-like kinase (ULK) complex (e.g., ULK1, FIP200, ATG13), autophagosome nucleation (Beclin 1, VPS34, VPS15, and ATG14), autophagosome elongation and maturation (e.g., ATG5, ATG12, ATL16L1, ATG8/microtubuleassociated protein 1 light chain 3 [LC3]), and induction of autophagosomes and fusion of autophagosomes with lysosomes (i.e., ATG9/mammalian Atg9 and vacuole membrane protein 1) $(59,62)$. Amongst these ATG proteins, LC3 is a well-defined protein, which is cleaved from a pro-form by Atg4 and then conjugated with phosphatidyl-ethanolamine by the sequential action of Atg7 and Atg3 (63) to form LC3-II (Figure 1). The conversion of LC3-I (unconjugated cytosolic form) to LC3-II (autophagosomal membraneassociated phosphatidylethanolamine-conjugated form) has been considered as a major feature of autophagosome formation. Additionally, SQSTM1/p62 has an ubiquitin binding domain and an LC3 interaction domain and thus can bring ubiquitinated cargos to the autophagosomes for autophagy.

Significant numbers of signaling molecules particularly cytokine have been shown to regulate autophagy $(52,64)$. For example, IL-10 and IL-10 receptor signaling inhibits the starvation induced autophagy of murine macrophages via class I phosphatidylinositol 3-kinase (PI3K) pathway (64), suggesting that IL-10 plays a critical role in the autophagic process of macrophages. Distinct classes of PI3K have previously been shown to be involved in signaling pathways that control macro-autophagy in human colon cancer HT-29 cells $(65,66)$. Moreover, the Th1 cytokine IFN-gamma induces autophagy in macrophages (67). In contrast, Th2 cytokines, IL-4 and IL-13, inhibit autophagy in macrophages under starvation or IFN-gamma stimulation, and inhibit autophagy-mediated killing of intracellular mycobacteria in murine and human macrophages (68). Intriguingly, recent studies suggest that IL4 can induce autophagy in activated $\mathrm{CD} 4^{+}$Th2 cells (68), primary dendritic cells (DCs) (69), and primary B cells that exacerbates experimental asthma through different mechanisms (70). Similarly, IL-13 alone can activate autophagy in airway epithelial cells and drive the secretion of excess mucus (71). These findings suggest that Th2 cytokines may play a dual role in autophagy induction depending on different cell types. However, further studies are essential to investigate how differential modulation of autophagy by Th1 and Th2 cytokines in different cell types, which may represent a key feature of the host response to environmental stresses. Furthermore, neutralization of the receptors VEGFR, $\beta$-integrin or CXCR4, or IL-10 can also regulate autophagy by restoring autophagy in macrophage/monocytic cells exposed to HIV-1-infected cells (72). In contrast, autophagy can also regulate cytokine production (73). For example, Atg16L1 is an essential component of the autophagic machinery responsible for control of the endotoxin-induced IL-1 $\beta$ production (74). It has also been shown that autophagy influences IL- $1 \beta$ secretion by either targeting pro-IL-1 $\beta$ for lysomal degradation or regulating activation of the NLRP3 inflammasome (73). Similarly, autophagy plays a pivotal role in the induction and regulation of IL-23 secretion and innate immune responses through effects on IL-1 secretion (75). Furthermore, autophagy regulates inflammatory cytokine secretion [e.g., macrophage migration inhibitory factor (MIF)] by macrophages through controlling mitochondrial ROS (76). ROS can activate STAT3 transcriptional factor, leading to the secretion of IL-6 in starvation-induced autophagy of cancer cells (77). Interestingly, Alternaria extract as a major outdoor allergen can activate autophagy that subsequently induces IL-18 release from airway epithelial cells (48).

In addition to cytokines, several significant molecules have also been identified to regulate autophagy (52). Of these, mTOR (mammalian target of rapamycin) has been shown to regulate cell-signaling pathways after exposure to several major factors including amino acids, oxidative stress, energy levels, and growth factors $(78,79)$. Particularly, mTORC1 (one of the functional forms of mTOR) regulates autophagy by directly interacting with the ULK complex ULK1-ATG13-FIP200 (80). mTORC1 can suppress autophagy by inhibiting ATG1/ULK complexes under normal physiological conditions (51). In addition, AMPactivated protein kinase (AMPK)/ULK1 pathway mediates autophagy by transmitting stress signals for autophagosome formation, independent of mTOR signaling $(80,81)$. AMPK is capable of inhibiting non-autophagy VPS34 complexes but activating the proautophagy VPS34 by the phosphorylation of Beclin 1 (Beclin1/VPS34) to initiate phagophore formation (82). In addition to AMPK and mTORC1, calmodulin-dependent protein kinase II (CaMKII) also plays a role in engaging autophagy regulation (83). CaMKII, a serine/threonine-specific 


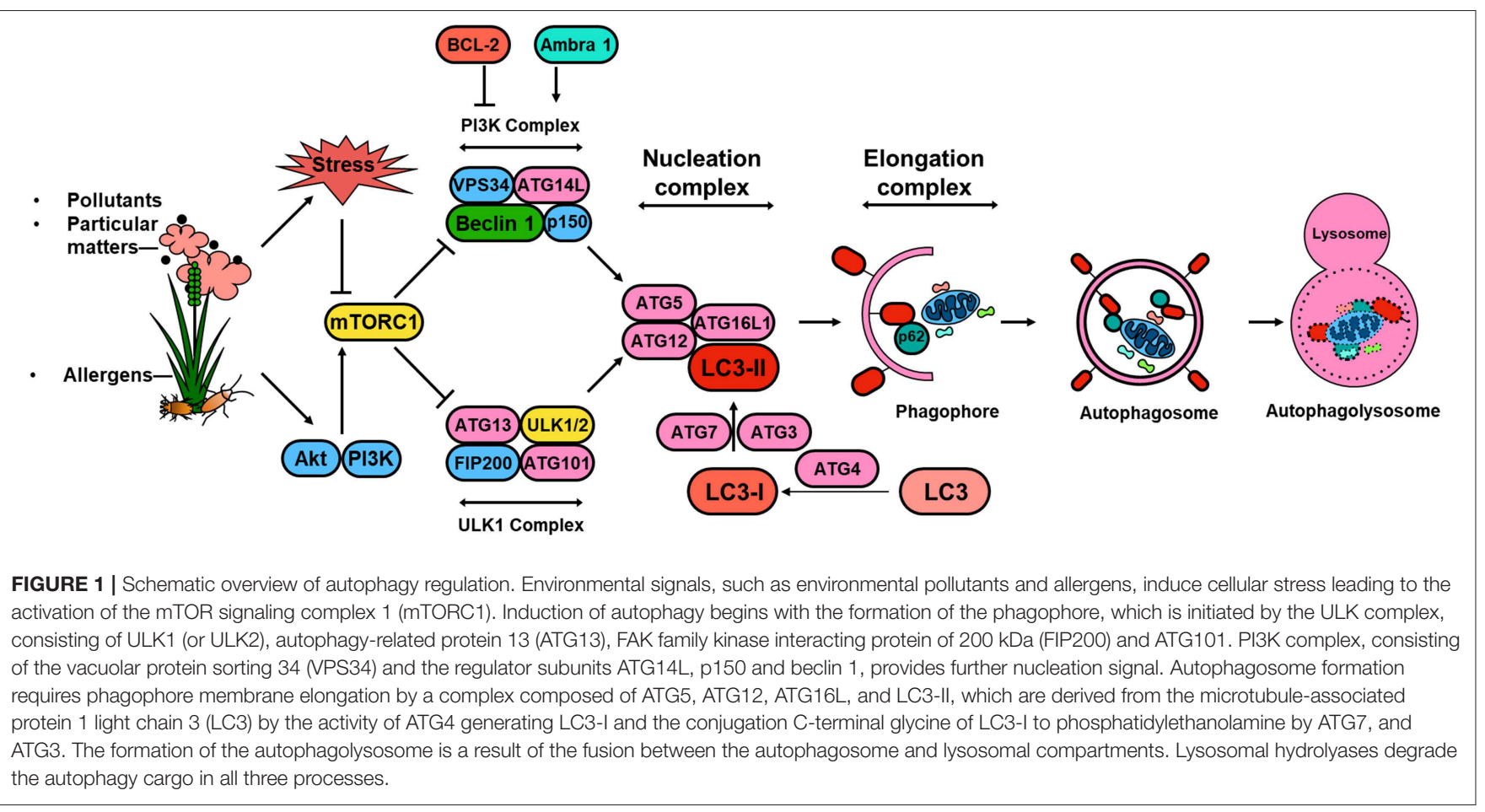

protein kinase regulated by the $\mathrm{Ca}^{2+} /$ calmodulin complex, can directly phosphorylate Beclin 1 at Ser90 that enhances K63linked ubiquitination of Beclin 1 and activation of autophagy (84). CaMKII can also stimulate K63-linked ubiquitination of inhibitor of differentiation $1 / 2$ (Id-1/2). Of interest, the increased ubiquitinated Id-1/Id-2 can bind p62 and then be transported to autolysosomes for degradation, which can subsequently promote the differentiation of neuroblastoma cells and suppress the proportion of stem-like cells (84).

Recently, transcriptional regulation of autophagy genes has drawn a lot of attention in autophagic responses to specific stimuli (85). Several transcription factors and histone modifications have been identified to regulate autophagy gene expression. In addition to the well-known two transcription factors, p53 and Forkhead box O3 (FOXO3) (86), Transcription Factor EB (TFEB) is one of the most recently identified transcriptional regulators of autophagy (87). TFEB is highly phosphorylated by various kinases such as AKT, Extracellular Signal-Regulated Kinase 2 (ERK2), and mTORC1, and sequestered in the cytoplasm under nutrient rich conditions. In contrast, TFEB is dephosphorylated by calcineurin $(\mathrm{CaN})$ and translocates to the nucleus where it activates autophagy and lysosome gene transcription upon nutrient deprivation (88). Forkhead box K (FOXK) engages in the transcriptional repression of autophagy gene expression by binding to promoter regions of early-stage autophagy genes (e.g., ULK complex) and recruits the SIN3A-Histone deacetylase (HDAC) repressor complex to these regions under nutrient rich conditions (89). However, most intriguingly, the posttranslational modification status on histones is also linked to autophagy gene regulation, including histone H4K16 acetylation,
H3K9 dimethylation, and H3K27 trimethylation (90). Of these, H4K16 acetylation suppresses autophagy gene expression through H4K16 acetyltransferase human Males absent On the First (hMOF) degradation and/or Sirtuin1 (SIRT1)-dependent histone deacetylation (91). H3K27 trimethylation catalyzed by Enhancer of Zeste Homolog 2 (EZH2) suppresses the expression of negative regulators of the mTORC1 signaling components and leads to mTORC1 activation and autophagy inhibition (92). Interestingly, many of the transcriptional factors that modulate expression of autophagy genes are regulated by common upstream kinases such as mTORC1 and AMPK. Furthermore, histone modification status is also a significant determinant of transcriptional regulators to autophagic stimuli.

\section{AUTOPHAGY AND KEY FEATURES OF ASTHMA}

Exposure to traffic and industrial pollution particulate matters, predominantly DEPs, have been shown to increase the risk of asthma $(15,26)$. Environmental pollutants (e.g., $\mathrm{PM}_{2.5}$ ) can induce ROS generation and impair lung function in asthmatic patients (93-97). It was well-documented that ROS are key mediators that contribute to oxidative damage and chronic airway inflammation in allergy and asthma (98-101). However, the underlying mechanisms still remain unclear. Recent studies have suggested that autophagy may be a new frontier in human asthma (50) and may play a crucial role in chronic airway inflammation (42). Indeed, higher autophagy levels have been shown in sputum granulocytes, peripheral blood cells and peripheral eosinophils of patients with severe asthma (102). 
The increased autophagy has been associated with important immune mechanisms and extracellular matrix deposition and fibrosis in airway remodeling in asthma (43). Furthermore, genetic mutations in autophagy genes have been associated with asthma. For example, single nucleotide polymorphisms in Atg5 are correlated with reduced lung function (103). Thus, these cumulative findings raise the possibility that environment/allergen exposure initiates the production of ROS in airway epithelial cells, which serve as "signaling molecules" modulating the process of autophagic cycle through activating signaling molecules and autophagy pathways, thereby leading to the major phenotypic changes of asthma as summarized in Figure 2, including airway inflammation, airway remodeling, and airway hyper-responsiveness.

\section{AUTOPHAGY AND AIRWAY INFLAMMATION}

Autophagy plays important roles in airway inflammation (36, 42). It has been suggested that autophagy plays a critical role in $\mathrm{PM}$-induced inflammation in airway epithelium through the activation of NF-kB1 and activator protein-1 (AP-1) (104). Furthermore, $\mathrm{PM}_{2.5}$ can induce inflammatory cytokine release (e.g., IL-6, IL-8, IL-1 $\beta 1$, and $\mathrm{TNF} \alpha$ ) and oxidative injury of lung cells (105). Additionally, Long et al. found that $\mathrm{PM}_{2.5}$ can induce cell arrest in the G0/G1 phase and increase mitochondrial membrane potential, ROS generation, and airway epithelial cell apoptosis (106). $\mathrm{PM}_{2.5}$ not only induced the production of proinflammatory cytokine IL-6, TNF $\alpha$, and activation of AMPK, but also promoted the expression of ATG5, Beclin-1 and LC3II in the airway epithelial cells (107). Interestingly, knockdown of ATG5 limited $\mathrm{PM}_{2.5}$-induced autophagy, ROS generation, cell apoptosis, and production of IL-6 and TNF $\alpha$. Mechanistically, this study suggests that the activation of AMPK may be critical in autophagy-mediated $\mathrm{PM}_{2.5}$-induced airway inflammation. In addition, allergens have also been shown to induce autophagy. OVA (ovalbumin) used in a murine asthma model can induce autophagy in airway tissues (36). Alternaria alternata as one of the major outdoor allergens that cause allergic airway diseases (108) has been shown to induce IL-18 secretion from airway epithelial cells, and thereby initiate Th2-type responses (109).

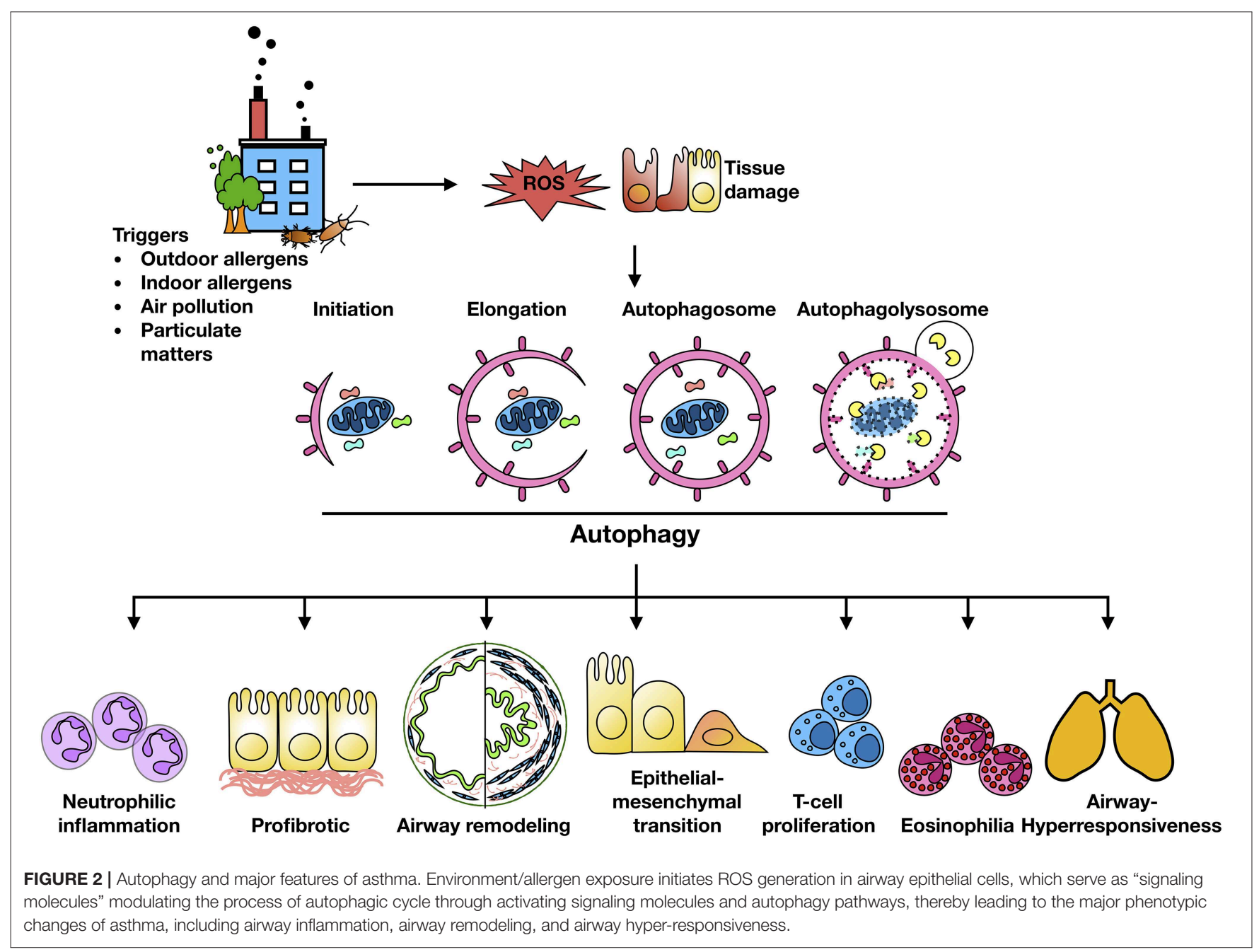


IL-18 is a pro-inflammatory cytokine that belongs to the IL1 family (110). Importantly, Alternaria extract stimulation can activate an autophagy-based unconventional secretion pathway and induce airway epithelial cells to release IL-18 via an autophagy dependent, but caspase 1 and 8 independent pathway (48). Studies from our research group showed that cockroach extract can induce autophagy in airway epithelial cells in vitro and in a mouse model of asthma (47). Further studies on the underlying mechanisms demonstrated that ROS and oxidized CaMKII (ox-CaMKII) in airway epithelial cells are critical in regulating cockroach allergen-induced autophagy (111).

Although environmental pollutants/allergens can induce autophagy, its role in airway inflammation remains unclear. It has been suggested that, at baseline, autophagy is critical for inhibiting spontaneous lung inflammation and is fundamental for airway mucus secretion by airway goblet cells. Autophagy deficient mice (Atg5 $5^{-/}$and $\operatorname{Atg} 7^{-/-}$) develop spontaneous sterile lung inflammation (110). Similarly, deficiency of CD11c-specific autophagy results in severe IL-17A-mediated neutrophilic lung inflammation and unprovoked spontaneous airway hyperactivity (112). Furthermore, deficiency of ATG5 in airway epithelial cells results in an increased airway inflammation (113), and disruption or deletion of autophagy in airway epithelial cells resulted in airway hyperreactivity (114). Autophagy deficiency (ER-Cre: Atg $7^{f l} / f l$ ) in mice after exposure to $P$. aeruginosa impairs pathogen clearance, increases neutrophilic inflammation, and the production of IL-1 $\beta$ (115). Although autophagy appears to be a protective mechanism, autophagy may also exacerbate airway inflammation. For example, inhibition of autophagy by 3-MA and intranasal knockdown of Atg 5 led to marked improvement in AHR, eosinophilia, IL-5 levels in bronchoalveolar lavage fluid, and histological inflammatory features (36). Similarly, autophagy deficiency in macrophages (siRNA targeting PIK3C3) during LPS-induced lung inflammation attenuates lung and bronchoalveolar immune cell infiltration and air space cytokine levels (116). Additionally, IL-4-induced autophagy in B cells exacerbated asthma through an mTOR-independent, PtdIns3K-dependent pathway (70). Thus, autophagy may play diverse roles, either protective or detrimental, in asthma. Although the reason is unknown, it has been suggested that autophagy may represent a protective role in maintaining homeostasis at baseline or during acute infection, but play a detrimental role due to impaired autophagy or a persistent autophagy responses leading to an accumulation of excessive autophagosome in a prolonged exposure of environmental pollutants/allergens or inflammation. Furthermore, autophagy involvement in different cell types may result in different characteristic phenotypic changes. For example, deletion of ATG5 and ATG14 or pharmacological inhibition (e.g., 3-MA, Baf-A1) in cultured airway epithelial cells treated with IL-13 results in less mucus secretion and less CCL26 secretion. In contrast, autophagy deficiency in macrophages (117) or DCs (112) results in the exacerbation of inflammation. Thus, the investigation of the real impact of autophagy, protective or detrimental, is extremely challenging.

\section{AUTOPHAGY AND AIRWAY REMODELING}

Recent studies have linked autophagy to the major features of airway remodeling in asthma, including airway smooth muscle (ASM) 44 (118-120), extracellular matrix (ECM) (121, 122), fibrosis (117), and epithelial-mesenchymal transition (EMT) (123). Particularly, it has been suggested that TGF $\beta 1$ induced autophagy is essential for collagen and fibronectin production in human airway smooth muscle cells, and deletion of Atg5 and Atg7 leads to reduction in pro-fibrotic signaling and ECM protein release $(50,124)$. In turn, autophagy has also been shown to participate in profibrotic changes induced by TGF $\beta 1$ (125). Furthermore, McAlinden et al. provided evidence of increased activation of the autophagy pathway in the airways of patients with asthma (43). Especially, they showed an association for TGF $\beta 1$ and accumulation of collagen and increased profibrotic signaling in an autophagy-dependent manner in ASM cells (43). Furthermore, inhibition of autophagy in murine model has been shown to attenuate airway inflammation and reduce the concentration of TGF $\beta 1$, and subsequently lead to a reduced airway remodeling. However, the critical mechanistic evidence is limited.

\section{MITOPHAGY}

Mitophagy is the selective degradation of mitochondria by autophagy. It often happens to damaged mitochondria following the exposure to environmental pollutants/allergens or stress and plays a critical role in promoting turnover of mitochondria and preventing accumulation of dysfunctional mitochondria (38). Mitochondrial dysfunction and elevated ROS production have been associated with allergic diseases, including atopy, atopic dermatitis, and asthma (126-129). Of interest, a disturbance in the homeostasis of mitochondria leads to ROS generation, which cause weakened barriers and subsequently airway inflammation, epithelial fragility, and impaired secretion capacity (130). Furthermore, $\mathrm{PM}_{2.5^{-}}$ exposed rat lung injury is associated with mitochondrial fusion-fission dysfunction, mitochondrial lipid peroxidation and cellular homeostasis imbalance, and ROS generation, leading to the disruption of mitochondrial dynamics (131). $\mathrm{PM}_{2.5}$ can regulate the dynamics of mitochondria via facilitating mitochondrial fission, and the excess ROS induced by $\mathrm{PM}_{2.5}$ can trigger mitophagy by activating PINK1/Parkin pathway (132). Acrolein, an ubiquitous environmental pollutant that is abundant in tobacco smoke, cooking fumes, and automobile fumes (133), has also been reported to induce mitochondrial DNA (mtDNA) damages, mitochondrial fission and mitophagy in human lung cells (134). Of interest, mitophagy was found to prevent mitochondria-induced inflammation (mito-inflammation) (135). Thus, mitophagy may be critical in environmental pollutant/allergen-induced mitochondrial dysfunction and dysregulation of mitochondrial bioenergetics. These may ultimately result in a dysregulated mitophagic cycle and significant phenotypic changes observed in asthma (Figure 3). 


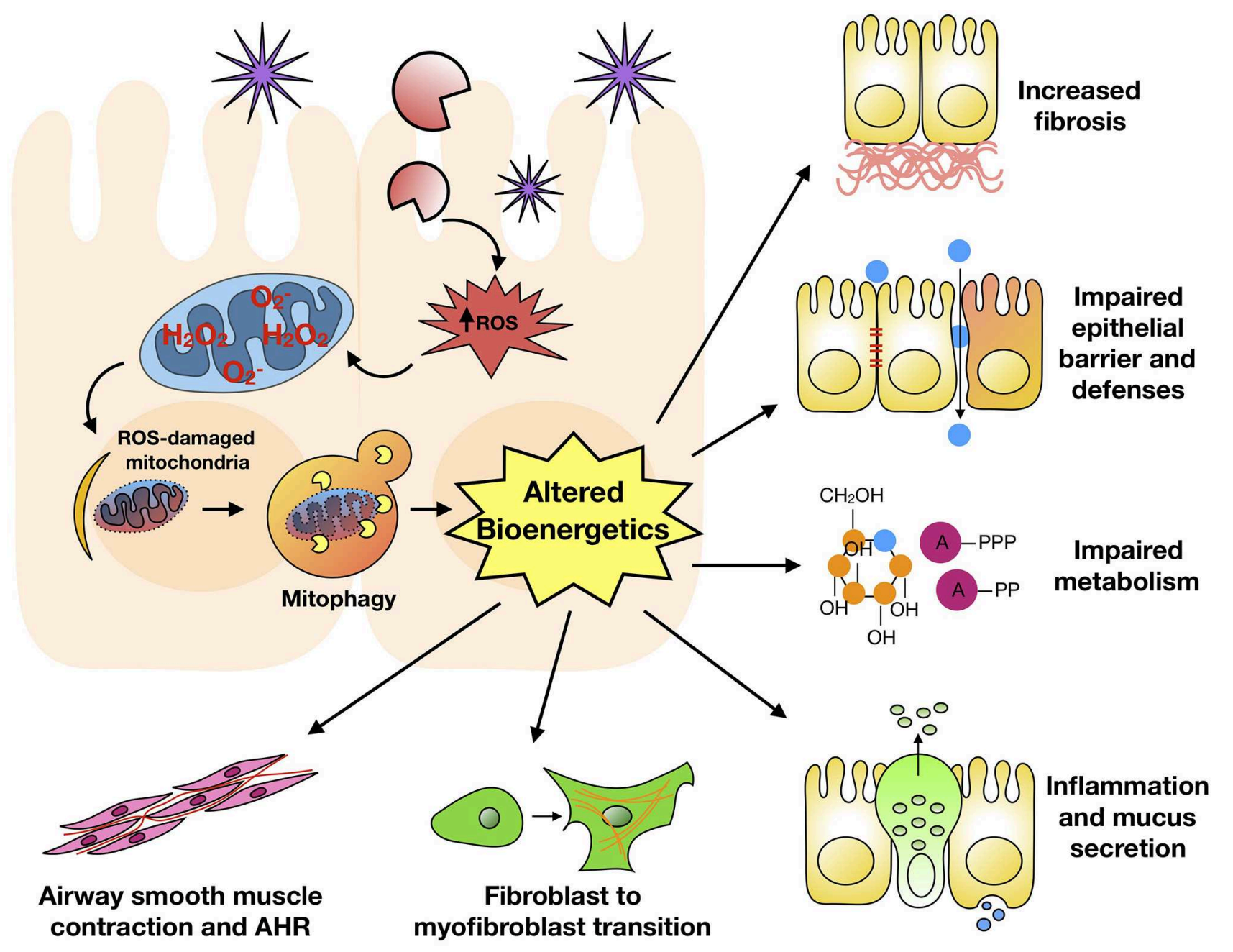

FIGURE 3 | Mitophagy and major features of asthma. Environmental pollutant/allergen induces excessive ROS generation, mitochondrial dysfunction, and mitophagy, subsequently leading to dysregulation of mitochondrial bioenergetics. These may ultimately result in significant phenotypic changes observed in asthma.

\section{MOLECULAR MECHANISMS OF MITOPHAGY}

Mitophagy is an evolutionarily conserved homeostatic process by which the cells selectively degrade only dysfunctional or damaged mitochondria (136, 137). Mitophagy is a normal physiological process during cell life and functions as surveiling mitochondrial population, eliminating superfluous and/or impaired organelles (137). Defective removal of damaged mitochondria leads to hyper-activation of inflammatory signaling pathways and subsequently to chronic systemic inflammation. However, important questions remain regarding the molecular mechanisms of mitophagy. It has been suggested that mitophagy is regulated by "PTEN-induced kinase 1 (PINK)Parkin-mediated pathway" and "receptor-mediated pathway" (137). Under physiological conditions, the transport of PINK1 preprotein onto the inner mitochondrial membrane (IMM) is followed by sequential proteolytic cleavage by the mitochondrial processing peptidase and pre-protein-associated rhomboidlike protease (138). Under challenged condition, active PINK1 accumulates on the outer mitochondrial membrane (OMM) through its interaction with the translocations of the outer mitochondrial membrane complex (TOM complex), promoting Parkin recruitment through phosphoralation of both Parkin and ubiquitin (139). In turn, Parkin triggers the polyubiqutination of several OMM proteins, including voltagedependent-anion-selective channer 1 (VDAC1), mitofusin 1 and $2(\mathrm{MFN} 1 / 2)$, and mitochondrial import receptor subunit TOM20 homolog (TOMM20) 138. Several adaptor molecules [e.g., p62, optineurin (OPTN), and nuclear domain protein 52 (NDP52)] bindphosphorylated polyubiqutinated proteins and initiate autophagosomal formation through binding with LC3 (140). Recent studies suggest that both NDP5 and OPTN are phosphorylated by the Tank-binding kinase 1 (TBK-1) which enhances their binding affinity to ubiquitin (141). The OPTN-TBK1 complex forms a feed-forward mechanism that 
speeds up the mitochondrial clearance (142). In contrast, the receptor-mediated mitophagy is dependent on various OMM proteins such as Nip3-like protein X (NIX), BCL2 interacting protein 3 (BNIP3), and Fun14 domain-containing protein 1 (FUNDC 1) $(137,140)$. These proteins localize to the OMM and interact directly with LC3 to regulate mitochondrial elimination. Cardiolipin and prohibitin 2 (PHB2) are externalized to OMM and interact with LC3 in response to mitochondrial damage to promote the engulfment of defective mitochondria $(143,144)$.

\section{MITOPHAGY AND ASTHMA}

Similar to autophagy, accumulating evidence suggests that both enhanced and impaired mitophagy has an important role in the pathogenesis of COPD and lung fibrosis (145149). However, limited studies were found for asthma. Recent studies have shown that $\mathrm{PM}_{2.5}$ can induce increased ROS and mitochondrial damage, which triggers the mitophagy through activating PINK/Parkin pathway (132). In the nucleus, excessive ROS could activate HIF-1 FOXO3, and NRF2, which promote the transcription of BNIP33/NIX, LC3/BNIP3, and p62, thereby facilitate mitophagy (150). Furthermore, the impairment of mitochondrial degradation by mitophagy can lead to the accumulation of fragmented mitochondria and activation of the mitochondrial apoptosis pathway (134). Thus, these studies suggest that environmental pollutants can induce ROS and mitochondrial damage, which triggers mitophagy to maintain stable mitochondrial function in cells by scavenging impaired mitochondria and reducing excessive ROS. Further studies on regulatory mechanisms regarding ROS and mitophagy may provide a new angle on therapies for allergy and asthma.

\section{CELLULAR SENESCENCE}

Cellular senescence is characterized by irreversible cell cycle arrest and triggered by a number of factors such as aging, DNA damage, oxidative stress, mitochondrial dysfunction (151-153), telomere shortening $(154,155)$, epigenetic modifications (156), and inflammation (157). Senescence arrest occurs mostly in the G1 phase of the cell cycle, distinguishing it from G0-arrested quiescent cells, and is mediated by cyclin-dependent kinase inhibitors (CDKis) (e.g., p2 $1^{\mathrm{CIP} 1}, \mathrm{p} 16^{\mathrm{INK} 4 \mathrm{a}}$ ) and is dependent on the TP53 and pRB tumor suppressor pathways (158). Also, telomeres and nucleoprotein complexes located at the ends of linear chromosomes (159) are critical to the cellular senescence (160). Furthermore, senescent cells accumulated in tissues secrete a large amount of pro-inflammatory mediators termed the senescence associated secretory phenotype (SASP), which drives chronic inflammation, leading to further senescence (157). The composition of the SASP is stimulus-dependent and includes pro- and anti-inflammatory cytokines, chemokines, matrix metalloproteinases, growth factors, and other factors, and has an important role in the immune-mediated clearance of senescent cells and tissue dysfunction (160). Senescent cells have been found at sites of chronic age-related diseases like osteoarthritis (161), atherosclerosis (162-164), and aging lung
(153), highlighting the significant role of senescent cells in the pathogenesis of chronic diseases. Senescent cells exhibit increased protein turnover and massive proteotoxic stress due to augmented autophagy and SASP component synthesis (165). Senescence cells also show increased rates of mitochondrial metabolic activity, including the tricarboxylic acid cycle, oxidative phosphorylation, and glycolytic pathways. Senescent cells have increased AMP/ADP:ATP and NAD+/NADH ratios, activating AMPK, which reinforces a TP53-dependent cellcycle arrest $(166,167)$. In addition, senescent cells do not proliferate, but are resistant to autophagy and apoptosis, and are thus long living. Importantly, senescent cells can exacerbate mitochondrial dysfunction, inflammation, and other diseasepromoting pathways through SASP (153).

Accumulation of senescent cells may slow or stop cell regeneration and tissue maintenance, thus leading to tissue aging (166). Indeed, clearing senescent cells from tissues of mouse models was shown sufficient to delay, prevent, or alleviate multiple age-related disorders (168). Although the underlying mechanisms regarding the elimination of senescent cells are poorly understood, the immune system has been recognized to be critical (169). Different immune cells have been suggested to be involved in the surveillance of senescent cells, including neutrophils, macrophages, natural killer cells, and $\mathrm{CD}^{+}{ }^{+} \mathrm{T}$ cells (170). These immune cell-derived senescent cells can be immunogenic by expressing stimulatory ligands (e.g., MICA/B) that bind to NKG2D and activating their killing by NK cells (171). Furthermore, senescent cells can recruit immune cells to eliminate senescent cells by secreting cytokine and chemokines (172). Interestingly, recent studies support a balance between activating and inhibitory signals that will determine whether NK and T-cells respond to senescent cells. These studies also suggest a novel mechanism whereby the increased expression of HLA$\mathrm{E}$ on senescent fibroblasts reduced the clearance of senescent cells by $\mathrm{NK}$ and $\mathrm{CD}^{+} \mathrm{T}$ cells expressing inhibitory receptor NKG2A (157). This represents a novel therapeutic approach to improve the immune clearance of senescent cells by blocking the interaction between HAL-E and NKG2A. In addition, the SASPrelated cytokine IL- 6 contributes to the increased expression of HAL-E in senescent cells, and that persistent inflammation may result in remaining of senescent cells in tissues, further contributing to the diseases.

\section{CELLULAR SENESCENCE AND ASTHMA}

Mitochondrial dysfunction has been demonstrated to be able to drive a cell into premature senescence, which affects airway diseases $(151,152)$. Indeed, the potential role of cell senescence in the pathogenesis of asthma has drawn great attention (162). Studies have implicated that cell senescence in the lung may be an important risk factor for the development of asthma $(39,173)$. Both COPD and idiopathic pulmonary fibrosis (IPF) are increased in prevalence with age and have been associated with senescence $(174,175)$. Senescence-related changes are also found in the lungs of adults with asthma, and in the airways of asthmatic children (176). However, mechanistic links 
between environmental pollutants, allergens, senescence, and pathophysiology of asthma have not been established. Studies have demonstrated that exposure to $\mathrm{PM}_{2.5}$ can induce senescence of human dermal fibroblasts (177). Increased exposure to $\mathrm{PM}_{2.5}$ is correlated with shortened telomeres in placental tissues and umbilical cord blood (178). Similarly, Bisphenol A (BPA) can induce Th2 inflammatory cascade and trigger DSB-ATMp53 signaling pathway leading to cell cycle arrest, senescence, autophagy, and stress response in human fetal lung fibroblasts (179). Telomeres are critical to the cellular senescence (160), and telomere shortening is a strong indication of cellular senescence. In a study of 730 mother-baby pairs, increased exposure to $\mathrm{PM}_{2.5}$ has been shown to correlate with shortened telomeres in placental tissue and umbilical blood (178). Telomere shortening was also associated with airway hyper-responsiveness and is an inducer of accelerated replicative senescence of bronchial fibroblasts in patients with asthma (154). This was supported by findings in the chronic asthmatic patients who also displayed shorter telomere lengths and suggested that asthma chronicity may be associated with telomere length even at early ages (155). Furthermore, TSLP-induced cellular senescence with elevated p21 and p16 in human epithelial cells was essential for airway remodeling in vitro (39). This was further supported by the fact that inhibition of TSLP signaling attenuates epithelial senescence, airway hyper-reactivity, and airway remodeling in an OVA mouse model (39). Plasminogen activator inhibitor (PAI-1), a wellknown cell senescence and fibrosis mediator, could activate p53 and mediate bleomycine- and doxorubicin-induced alveolar type II (ATII) cell senescence (180). Further studies suggest that PAI1 mediates TGF- $\beta 1$-induced ATII cell senescence, which may contribute to lung fibrogenesis in part by activating alveolar macrophages via secreting pro-fibrotic and pro-inflammatory mediators. Interestingly, this effect is highly dependent on the target cell, because it seems that PAI-1 has opposite effects on fibroblasts and ATII cells in patients with IPF (181). Together, these findings suggest a significant role of senescence in airway fibrosis and remodeling.

Many studies also support the rationale that senescence is associated with a higher pro-inflammatory cytokine profile (182). Of note, higher amounts of IL-6 have been found in patients with asthma and have been shown to trigger or to reinforce premature cellular senescence (183). This IL-6 driven immune-senescence may serve as part of a feed forward loop that drives asthma progression and reduces the efficacy of antiinflammatory treatments. SASPs released from senescent cells contain inflammatory cytokines that may increase inflammation and impair cellular function in asthma. Furthermore, elevated p21 expression in asthmatic epithelium is not reduced with corticosteroid treatment (40), and in turn, loss of $\mathrm{p} 16^{\mathrm{INK} 4 \mathrm{a}}$ protein results in decreased cell sensitivity to dexamethasone treatment (184), raising the possibility that senescence may play an important role in glucocorticoid resistance in the patients with asthma. Indeed, lymphocyte senescence in COPD has been suggested to be associated with loss of glucocorticoid receptor (GCR) expression by pro-inflammatory/cytotoxic lymphocytes (185). Thus, investigation into the role of senescence in glucocorticoid resistance may provide novel approaches for the treatment of asthma. In addition, although current studies suggest a role of senescence in asthma, little is known about the pathway regarding the environmental pollutants/allergens, ROS, mitochondrial dysfunction, and senescence. Furthermore, it is poorly understood about the mechanistic links between cell senescence and asthma pathophysiology. Additionally, asthma is typically associated with an imbalance between Th1 and Th2 pathways, and over-driven Th2-mediated inflammation can result in airway inflammation and asthma (186). On the other hand, immune-senescence has been associated with lung aging, and that altered Th1/Th2 imbalance may contribute to the process of accelerated lung aging and immune-senescence (187). Indeed, with aging, mouse lungs showed typically increased Th1 cells with increased levels of IFN-gamma. However, the link between Th1/Th2 cells and senescence remains largely un-explored. Thus, further research is needed to establish the mechanistic links between increased cytokines with aging and senescent cell induction, and asthma pathophysiology.

\section{AUTOPHAGY/MITOPHAGY AND CELLULAR SENESCENCE}

Autophagy plays a role in homeostatic energy supply and elimination of aggregate-prone proteins, damaged organelles, and intracellular microbes. Autophagy also plays a critical role in the regulation of innate and adaptive immune responses in response to environmental stresses. In contrast, cellular senescence is caused by insufficient regulatory mechanisms of homeostasis. One of the most common causes for cellular senescence is that mitochondrial dysfunction results in cellular senescence due to excessive ROS production (153). Although autophagy and senescence are known to share similar properties, recent studies suggest a "double-edged" sword that autophagy can either accelerate the development of senescence or prevent senescence $(188,189)$. Especially, autophagy can produce large amounts of recycled amino acids, which trigger the production of SASP (e.g., IL-6, IL-8) through the activation of mTOR, thereby leading to senescence (190). By contrast, inhibition of autophagy or insufficient autophagy may promote cell senescence (190). Recent studies suggest that autophagy could be either pro-senescent or anti-senescent, depending on the type of autophagy (general or selective), stimulatory signals, and can be cell-type specific (189). Although it seems that autophagy and senescence are highly related, a great deal of questions remain unanswered regarding the mutual relationship between autophagy and senescence at both molecular and cellular levels in diseases like asthma.

\section{THERAPEUTIC INTERVENTIONS}

Autophagy, mitophagy, and cellular senescence are potential targets that can be manipulated at various levels, and inhibition of these processes have been considered as potential therapeutic strategies. For example, Liu et al. found that 3-methyladenine (3-MA), an inhibitor of autophagy, suppresses the formation of autophagosomes through the inhibition of PI3K (36). 
Chloroquine (CQ), another inhibitor of autophagy, also has the ability to inhibit HDM-induced airway remodeling through modulating autophagy pathways (191). In addition, bafilomycine (Baf-A), a macrolide antibiotic derived from Streptomyces griseus, can block late-phase autophagy through significant cytosolic acidification (192). In addition, administration of drugs currently in use for asthma (e.g., dexamethasone, montelukast, anti-IL-5, and anti-IgE antibody) can also inhibit autophagy (36). However, these current drugs for autophagy are far from specific, and may play a dual role in modulation of autophagy. Thus, addressing the real impact of autophagy in activation or inhibition of inflammation in disease models is challenging.

It has also been suggested that targeting mitophagy may possess therapeutic potential. Rapamycin and metformin as general autophagy-inducing drugs have been shown to attenuate AMPK and mTOR activity, and preserve energy metabolism through regulating mitophagy and mitochondrial biogenesis stimulation $(193,194)$. Of note, administration of metformin can induce mitophagy by promoting Parkin activity through p53 downregulation. In addition, several naturally occurring compounds, such as spermidine, resveratrol, urolithin $\mathrm{A}$ and antibiotics, have been demonstrated to maintain mitochondrial integrity by the induction of mitophagy and promotion of mitochondrial biogenesis (137). However, the therapeutic potential in human diseases still remains to be determined. Thus, identification of mitophagy modulators may result in therapeutic intervention strategies by targeting mitochondrialassociated pathologenesis of diseases.

Lastly, there is ongoing research to target senescence in cases of pulmonary fibrosis and asthma (195). Specifically, patients with age-related lung diseases (such as COPD and asthma) showed high levels of oxidative stress in the lung tissues, Thus, patients with COPD or asthma could benefit from the use of antioxidants (e.g., NAC, Nrf2 activators, NOX-4 inhibitors, MitoQ), which suppress inflammation and reduce the progression of senescence-associated pathways (196).

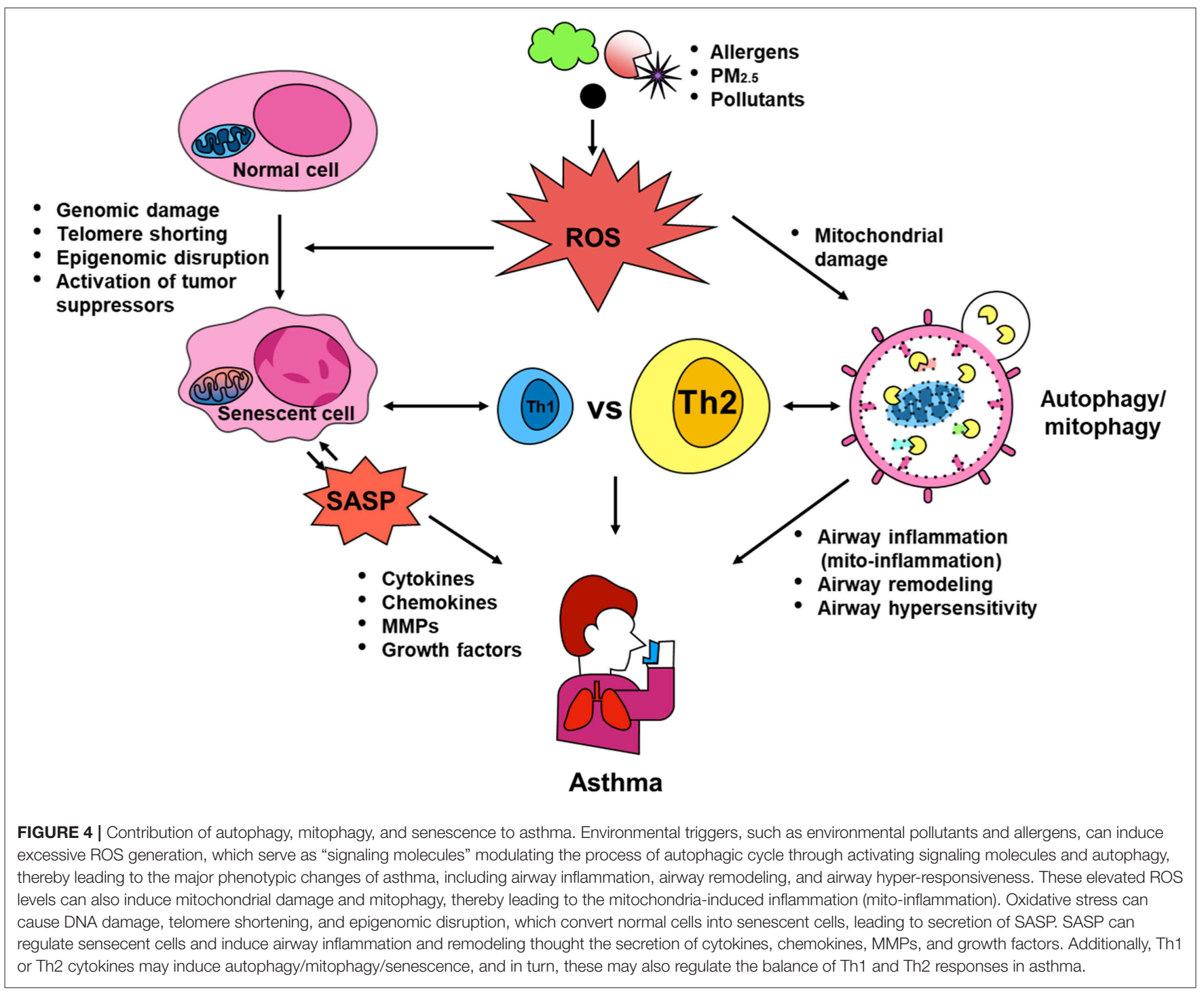


Moreover, orchestrating SASP modulation could be a better strategy. Indeed, rapamycin, metformin, sirtuin activators, or PAI-1 inhibitor have been suggested to have beneficial effects due to their ability to act as a SASP suppressor $(160,181)$. For example, mTOR activation has been shown to be essential for asthma onset (197), and inhibition of mTOR with rapamycin can suppress IL-1 translation and reduce mRNA stability of SASP factors (198). Similarly, metformin can also inhibit mTOR and could have the potential to inhibit SASP in asthma. Furthermore, specific induction of apoptosis in senescent cells using senolytics could also lead to beneficial effects (175). Additionally, inducing senescence cell clearance [e.g., ABT-263, also known as navitoclax (199)] by manipulating the immune system to recognize and clear these cells is also an important therapeutic approach. However, these current drugs are far from specific, and some of them may have off-target effects. For example, metformin and sirt 1 are also complex I inhibitor, which can promote mitochondrial fission and ROS production and subsequently cell senescence. Furthermore, although SASP is critical for the immune-mediated clearance of senescent cells, it also contributes to tissue dysfunction. Similarly, accumulation of senescent cells with time may lead to age-related loss of structure and tissue function $(160,200)$. By contrast, senescence can be beneficial in inhibiting the proliferation of transformed cells, and in some of key biological processes such as tissue repairing and wound healing (164). Because of these opposing effects, further studies are clearly needed to understand the exact role of senescence in diseases. Particularly, understanding of the molecular mechanisms regarding the processes involved in senescence will be helpful for the identification of modulators of cellular senescence, which could serve as therapeutic targets for senescence-associated diseases in the future.

\section{CONCLUSIONS}

Dysregulations in autophagy, mitophagy, and cellular senescence have been associated with environmental pollutant/allergeninduced oxidative stress, mitochondrial dysfunction, secretion of multiple inflammatory proteins known as SASP, and development of asthma. $\mathrm{PM}_{2.5}$ was reported to induce autophagy through activating AMPK (107), and to drive the mitophagy through activating PINK/Parkin pathway (132). $\mathrm{PM}_{2.5}$ was also shown to induce senescence of human dermal fibroblasts (177), while increased $\mathrm{PM}_{2.5}$ exposure was correlated with shortened telomeres in placental tissue and umbilical blood

\section{REFERENCES}

1. Akinbami LJ, Moorman JE, Bailey C, Zahran HS, King M, Johnson CA, et al. Trends in asthma prevalence, health care use, and mortality in the United States, 2001-2010. NCHS Data Brief. (2012):1-8.

2. World Health Organisation. Asthma. (2017). Available online at:https:// www.who.int/news-room/fact-sheets/detail/asthma

3. Masoli M, Fabian D, Holt S, Beasley R. The global burden of asthma: executive summary of the GINA Dissemination Committee report. Allergy. (2004) 59:469-78. doi: 10.1111/j.1398-9995.2004.00526.x
(178). Intriguingly, allergens, including OVA (36), A. alternata (48), and cockroach allergen $(47,111)$, have also been shown to induce autophagy through activating different signaling pathways. Thus, as hypothesized in Figure 4, environmental triggers, e.g., environmental pollutants or allergens, can induce ROS generation, which serve as "signaling molecules" modulating the process of autophagy through activating downstream signaling molecules and autophagy, thereby leading to the major phenotypic changes of asthma, including airway inflammation, airway remodeling, and airway hyperresponsiveness. These elevated ROS levels can also induce mitochondrial damage, thereby leading to the mitochondriainduced inflammation (mito-inflammation) and major features of asthma. Furthermore, oxidative stress can also cause DNA damage, telomere shortening, and epigenomic disruption, all of which induce cell cycle arrest and cellular senescence. Senescent cells can secrete SASP, which contains multiple inflammatory cytokines, chemokines, mtrix metalloproteinases (MMPs), and growth factors. The SASP leads to airway inflammation and remodeling. In turn, the SASP can also induce senescence and senescent cells can secrete ROS, which further promote the process of senescence. In addition, Th1 or Th2 cytokines may induce autophagy/mitophagy/senescence, and in turn, this autophagy/mitophagy/ senescence may also regulate the balance of Th1 and Th2 responses in asthma. Although comprehensive studies have been focused on investigating the role of autophagy, mitophagy and cellular senescence in the pathogenesis of diseases (e.g., beneficial or detrimental), many questions still remain untouched and unanswered. Thus, future studies are clearly needed to better understand these cellular processes, particularly after exposure to environmental pollutants and allergens, and to identify the therapeutic targets to regulate the autophagy/mitophagy/ senescence-associated asthma.

\section{AUTHOR CONTRIBUTIONS}

$\mathrm{KS}, \mathrm{YZ}, \mathrm{XH}$, and JC wrote the manuscript. DD and PG reviewed the manuscript.

\section{FUNDING}

This work was supported by grants from the US National Institutes of Health (NIH) (R56 AI143668, R21 AI109062, R21 AI137547, and R01AI141642).
4. Eder W, Ege MJ, von Mutius E. The asthma epidemic. N Engl J Med. (2006) 355:2226-35. doi: 10.1056/NEJMra054308

5. Hansel NN, McCormack MC, Belli AJ, Matsui EC, Peng RD, Aloe C, et al. Inhome air pollution is linked to respiratory morbidity in former smokers with chronic obstructive pulmonary disease. Am J Respir Crit Care Med. (2013) 187:1085-90. doi: 10.1164/rccm.201211-1987OC

6. Hao Y, Balluz L, Strosnider H, Wen XJ, Li C, Qualters JR. Ozone, fine particulate matter, and chronic lower respiratory disease mortality in the United States. Am J Respir Crit Care Med. (2015) 192:337-41. doi: $10.1164 / \mathrm{rccm} .201410-1852 \mathrm{OC}$ 
7. Mukherjee A, Agrawal M. Use of GLM approach to assess the responses of tropical trees to urban air pollution in relation to leaf functional traits and tree characteristics. Ecotoxicol Environ Saf. (2018) 152:42-54. doi: 10.1016/j.ecoenv.2018.01.038

8. Mukherjee A, Agrawal M. Global perspective of fine particulate matter pollution and its health effects. Rev Environ Contam Toxicol. (2018) 244:551. doi: 10.1007/398_2017_3

9. Wu JZ, Ge DD, Zhou LF, Hou LY, Zhou Y, Li QY. Effects of particulate matter on allergic respiratory diseases. Chronic Dis Transl Med. (2018) 4:95-102. doi: 10.1016/j.cdtm.2018.04.001

10. Murrison LB, Brandt EB, Myers JB, Hershey GKK. Environmental exposures and mechanisms in allergy and asthma development. J Clin Invest. (2019) 129:1504-15. doi: 10.1172/JCI124612

11. Wilson D, Takahashi K, Pan G, Chan CC, Zhang S, Feng Y, et al. Respiratory symptoms among residents of a heavy-industry province in China: prevalence and risk factors. Respir Med. (2008) 102:1536-44. doi: 10.1016/j.rmed.2008.06.010

12. Liu F, Zhao Y, Liu YQ, Liu Y, Sun J, Huang MM, et al. Asthma and asthma related symptoms in 23,326 Chinese children in relation to indoor and outdoor environmental factors: the Seven Northeastern Cities (SNEC) study. Sci Total Environ. (2014) 497-8:10-7. doi: 10.1016/j.scitotenv.2014.07.096

13. Brandt EB, Myers JM, Ryan PH, Hershey GK. Air pollution and allergic diseases. Curr Opin Pediatr. (2015) 27:724-35. doi: 10.1097/MOP.0000000000000286

14. Gowers AM, Cullinan P, Ayres JG, Anderson HR, Strachan DP, Holgate ST, et al. Does outdoor air pollution induce new cases of asthma? Biological plausibility and evidence; a review. Respirology. (2012) 17:887-98. doi: 10.1111/j.1440-1843.2012.02195.x

15. Guarnieri M, Balmes JR. Outdoor air pollution and asthma. Lancet. (2014) 383:1581-92. doi: 10.1016/S0140-6736(14)60617-6

16. Berhane K, Chang CC, McConnell R, Gauderman WJ, Avol E, Rapapport E, et al. Association of changes in air quality with bronchitic symptoms in children in California, 1993-2012. JAMA. (2016) 315:1491-501. doi: $10.1001 /$ jama.2016.3444

17. Li T, Hu R, Chen Z, Li Q, Huang S, Zhu Z, et al. Fine particulate matter $\left(\mathrm{PM}_{2.5}\right)$ : the culprit for chronic lung diseases in China. Chronic Dis Transl Med. (2018) 4:176-86. doi: 10.1016/j.cdtm.2018.07.002

18. Chen F, Lin Z, Chen R, Norback D, Liu C, Kan H, et al. The effects of $\mathrm{PM}_{2.5}$ on asthmatic and allergic diseases or symptoms in preschool children of six Chinese cities, based on China, Children, Homes and Health (CCHH) project. Environ Pollut. (2018) 232:329-37. doi: 10.1016/j.envpol.2017.08.072

19. Jin L, Xie J, Wong CKC, Chan SKY, Abbaszade G, Schnelle-Kreis J, et al. Contributions of city-specific fine particulate matter $\left(\mathrm{PM}_{2.5}\right)$ to differential in vitro oxidative stress and toxicity implications between Beijing and Guangzhou of China. Environ Sci Technol. (2019) 53:2881-91. doi: $10.1021 /$ acs.est.9b00449

20. Jung KH, Torrone D, Lovinsky-Desir S, Perzanowski M, Bautista J, Jezioro $\mathrm{JR}$, et al. Short-term exposure to $\mathrm{PM}_{2.5}$ and vanadium and changes in asthma gene DNA methylation and lung function decrements among urban children. Respir Res. (2017) 18:63. doi: 10.1186/s12931-017-0550-9

21. Miller RL, Peden DB. Environmental effects on immune responses in patients with atopy and asthma. J Allergy Clin Immunol. (2014) 134:1001-8. doi: 10.1016/j.jaci.2014.07.064

22. Kanchongkittiphon W, Mendell MJ, Gaffin JM, Wang G, Phipatanakul W. Indoor environmental exposures and exacerbation of asthma: an update to the 2000 review by the institute of medicine. Environ Health Perspect. (2015) 123:6-20. doi: 10.1289/ehp.1307922

23. Kanchongkittiphon W, Gaffin JM, Phipatanakul W. The indoor environment and inner-city childhood asthma. Asian Pac J Allergy Immunol. (2014) 32:103-10.

24. Finkelman FD. Diesel exhaust particle exposure during pregnancy promotes development of asthma and atopy. J Allergy Clin Immunol. (2014) 134:73-4. doi: 10.1016/j.jaci.2014.04.002

25. Jedrychowski WA, Perera FP, Maugeri U, Mrozek-Budzyn D, Mroz E, Klimaszewska-Rembiasz $\mathrm{M}$, et al. Intrauterine exposure to polycyclic aromatic hydrocarbons, fine particulate matter and early wheeze. Prospective birth cohort study in 4-year olds. Pediatr Allergy Immunol. (2010) $21(4 \mathrm{Pt}$ 2):e723-32. doi: 10.1111/j.1399-3038.2010.01034.x
26. Acciani TH, Brandt EB, Khurana Hershey GK, Le Cras TD. Diesel exhaust particle exposure increases severity of allergic asthma in young mice. Clin Exp Allergy. (2013) 43:1406-18. doi: 10.1111/cea.12200

27. Brandt EB, Biagini Myers JM, Acciani TH, Ryan PH, Sivaprasad U, Ruff B, et al. Exposure to allergen and diesel exhaust particles potentiates secondary allergen-specific memory responses, promoting asthma susceptibility. $J$ Allergy Clin Immunol. (2015) 136:295-303.e7. doi: 10.1016/j.jaci.2014.11.043

28. Zhang X, Chen X, Weirauch MT, Zhang X, Burleson JD, Brandt EB, et al. Diesel exhaust and house dust mite allergen lead to common changes in the airway methylome and hydroxymethylome. Environ Epigenet. (2018) 4:dvy020. doi: 10.1093/eep/dvy020

29. Bolcas PE, Brandt EB, Zhang Z, Biagini Myers JM, Ruff BP, Khurana Hershey GK. Vitamin D supplementation attenuates asthma development following traffic-related particulate matter exposure. J Allergy Clin Immunol. (2019) 143:386-94.e3. doi: 10.1016/j.jaci.2018.04.042

30. Wang E, Liu X, Tu W, Do DC, Yu H, Yang L, et al. Benzo(a)pyrene facilitates dermatophagoides group 1 (Der f 1)-induced epithelial cytokine release through aryl hydrocarbon receptor in asthma. Allergy. (2019) 74:1675-90. doi: 10.1111/all.13784

31. Sun L, Fu J, Lin SH, Sun JL, Xia L, Lin CH, et al. $\mathrm{PM}_{2.5}$ disturbs the balance of Th17/Treg cells by targeting Got1 and HIF-1alpha in an asthma model. $J$ Allergy Clin Immunol. (2019) doi: 10.1016/j.jaci.2019.10.008

32. Warren KJ, Dickinson JD, Nelson AJ, Wyatt TA, Romberger DJ, Poole JA. Ovalbumin-sensitized mice have altered airway inflammation to agriculture organic dust. Respir Res. (2019) 20:51. doi: 10.1186/s12931-019-1015-0

33. Miraglia del Giudice M, Allegorico A, Parisi G, Galdo, F, Alterio E, Coronella, A, et al. Risk factors for asthma. Ital J Pediatr. (2014) 40(Suppl 1):A77. doi: 10.1186/1824-7288-40-S1-A77

34. Do DC, Zhao Y, Gao P. Cockroach allergen exposure and risk of asthma. Allergy. (2016) 71:463-74. doi: 10.1111/all.12827

35. Poon AH, Chouiali F, Tse SM, Litonjua AA, Hussain SN, Baglole CJ, et al. Genetic and histologic evidence for autophagy in asthma pathogenesis. J Allergy Clin Immunol. (2012) 129:569-71. doi: 10.1016/j.jaci.2011. 09.035

36. Liu JN, Suh DH, Trinh HK, Chwae YJ, Park HS, Shin YS. The role of autophagy in allergic inflammation: a new target for severe asthma. Exp Mol Med. (2016) 48:e243. doi: 10.1038/emm.2016.38

37. Rowlands DJ. Mitochondria dysfunction: a novel therapeutic target in pathological lung remodeling or bystander? Pharmacol Ther. (2016) 166:96105. doi: 10.1016/j.pharmthera.2016.06.019

38. Prakash YS, Pabelick CM, Sieck GC. Mitochondrial dysfunction in airway disease. Chest. (2017) 152:618-26. doi: 10.1016/j.chest.2017.03.020

39. Wu J, Dong F, Wang RA, Wang J, Zhao J, Yang M, et al. Central role of cellular senescence in TSLP-induced airway remodeling in asthma. PLoS ONE. (2013) 8:e77795. doi: 10.1371/journal.pone.0077795

40. Puddicombe SM, Torres-Lozano C, Richter A, Bucchieri F, Lordan JL, Howarth $\mathrm{PH}$, et al. Increased expression of p21(waf) cyclin-dependent kinase inhibitor in asthmatic bronchial epithelium. Am J Respir Cell Mol Biol. (2003) 28:61-8. doi: $10.1165 / \mathrm{rcmb} .4715$

41. Deretic V, Klionsky DJ. Autophagy and inflammation: a special review issue. Autophagy. (2018) 14:179-80. doi: 10.1080/15548627.2017.1412229

42. Lee J, Kim HS. The role of autophagy in eosinophilic airway inflammation. Immune Netw. (2019) 19:e5. doi: 10.4110/in.2019.19.e5

43. McAlinden KD, Deshpande DA, Ghavami S, Xenaki D, Sohal SS, Oliver BG, et al. Autophagy activation in asthma airways remodeling. Am J Respir Cell Mol Biol. (2018) 60:541-53. doi: 10.1165/rcmb.2018-0169OC

44. Liu T, Wu B, Wang Y, He H, Lin Z, Tan J, et al. Particulate matter 2.5 induces autophagy via inhibition of the phosphatidylinositol 3kinase/Akt/mammalian target of rapamycin kinase signaling pathway in human bronchial epithelial cells. Mol Med Rep. (2015) 12:1914-22. doi: $10.3892 / \mathrm{mmr} .2015 .3577$

45. Zhu XM, Wang Q, Xing WW, Long MH, Fu WL, Xia WR, et al. $\mathrm{PM}_{2.5}$ induces autophagy-mediated cell death via NOS2 signaling in human bronchial epithelium cells. Int J Biol Sci. (2018) 14:557-64. doi: $10.7150 /$ ijbs. 24546

46. Li R, Zhou R, Zhang J. Function of $\mathrm{PM}_{2.5}$ in the pathogenesis of lung cancer and chronic airway inflammatory diseases. Oncol Lett. (2018) 15:7506-14. doi: 10.3892/ol.2018.8355 
47. Zhao Y, Luo X, Qiu L, Do DC, Ke X, Zaccone E, et al. Aryl hydrocarbon receptor in airway epithelium exacerbates cockroach allergen-induced asthma through autophagy. J Allergy Clin Immunol. (2017) 139:AB268. doi: 10.1016/j.jaci.2016.12.863

48. Murai H, Okazaki S, Hayashi H, Kawakita A, Hosoki K, Yasutomi M, et al. Alternaria extract activates autophagy that induces IL-18 release from airway epithelial cells. Biochem Biophys Res Commun. (2015) 464:969-74. doi: 10.1016/j.bbrc.2015.05.076

49. Liu HX, Yan HY, Qu W, Wen X, Hou LF, Zhao WH, et al. Inhibition of thymocyte autophagy-associated CD4 $(+) \mathrm{T}$ thymopoiesis is involved in asthma susceptibility in mice exposed to caffeine prenatally. Arch Toxicol. (2019) 93:1323-35. doi: 10.1007/s00204-019-02418-5

50. Zeki AA, Yeganeh B, Kenyon NJ, Post M, Ghavami S. Autophagy in airway diseases: a new frontier in human asthma? Allergy. (2016) 71:5-14. doi: 10.1111/all.12761

51. Glick D, Barth S, Macleod KF. Autophagy: cellular and molecular mechanisms. J Pathol. (2010) 221:3-12. doi: 10.1002/path.2697

52. Ghosh R, Pattison JS. Macroautophagy and chaperone-mediated autophagy in heart failure: the known and the unknown. Oxid Med Cell Longev. (2018) 2018:8602041. doi: 10.1155/2018/8602041

53. Schulze H, Kolter T, Sandhoff K. Principles of lysosomal membrane degradation: cellular topology and biochemistry of lysosomal lipid degradation. Biochim Biophys Acta. (2009) 1793:674-83. doi: 10.1016/j.bbamcr.2008.09.020

54. Ryter SW, Choi AM. Autophagy in lung disease pathogenesis and therapeutics. Redox Biol. (2015) 4:215-25. doi: 10.1016/j.redox.2014.12.010

55. Klionsky DJ, Abdelmohsen K, Abe A, Abedin MJ, Abeliovich H, Acevedo Arozena A, et al. Guidelines for the use and interpretation of assays for monitoring autophagy (3rd edition). Autophagy. (2016) 12:1-222. doi: 10.1080/15548627.2015

56. Li WW, Li J, Bao JK. Microautophagy: lesser-known self-eating. Cell Mol Life Sci. (2012) 69:1125-36. doi: 10.1007/s00018-011-0865-5

57. Kaushik S, Cuervo AM. Chaperone-mediated autophagy: a unique way to enter the lysosome world. Trends Cell Biol. (2012) 22:407-17. doi: 10.1016/j.tcb.2012.05.006

58. Cuervo AM, Wong E. Chaperone-mediated autophagy: roles in disease and aging. Cell Res. (2014) 24:92-104. doi: 10.1038/cr.2013.153

59. Levine B, Kroemer G. Biological functions of autophagy genes: a disease perspective. Cell. (2019) 176:11-42. doi: 10.1016/j.cell.2018.09.048

60. Jiang P, Mizushima N. Autophagy and human diseases. Cell Res. (2014) 24:69-79. doi: 10.1038/cr.2013.161

61. van Beek N, Klionsky DJ, Reggiori F. Genetic aberrations in macroautophagy genes leading to diseases. Biochim Biophys Acta Mol Cell Res. (2018) 1865:803-16. doi: 10.1016/j.bbamcr.2018.03.002

62. Qian M, Fang X, Wang X. Autophagy and inflammation. Clin Transl Med. (2017) 6:24. doi: 10.1186/s40169-017-0154-5

63. He C, Klionsky DJ. Regulation mechanisms and signaling pathways of autophagy. Annu Rev Genet. (2009) 43:67-93. doi: 10.1146/annurev-genet-102808-114910

64. Park HJ, Lee SJ, Kim SH, Han J, Bae J, Kim SJ, et al. IL-10 inhibits the starvation induced autophagy in macrophages via class I phosphatidylinositol 3-kinase (PI3K) pathway. Mol Immunol. (2011) 48:720-7. doi: 10.1016/j.molimm.2010.10.020

65. Petiot A, Ogier-Denis E, Blommaart EF, Meijer AJ, Codogno P. Distinct classes of phosphatidylinositol 3'-kinases are involved in signaling pathways that control macroautophagy in HT-29 cells. J Biol Chem. (2000) 275:992-8. doi: $10.1074 /$ jbc.275.2.992

66. Arico S, Petiot A, Bauvy C, Dubbelhuis PF, Meijer AJ, Codogno P, et al. The tumor suppressor PTEN positively regulates macroautophagy by inhibiting the phosphatidylinositol 3-kinase/protein kinase B pathway. J Biol Chem. (2001) 276:35243-6. doi: 10.1074/jbc.C100319200

67. Rovetta AI, Peña D, Hernández Del Pino RE, Recalde GM, Pellegrini J, Bigi $\mathrm{F}$, et al. IFNG-mediated immune responses enhance autophagy against Mycobacterium tuberculosis antigens in patients with active tuberculosis. Autophagy. (2014) 10:2109-21. doi: 10.4161/15548627.2014.981791

68. Botbol Y, Patel B, Macian F. Common gamma-chain cytokine signaling is required for macroautophagy induction during CD4+ T-cell activation. Autophagy. (2015) 11:1864-77. doi: 10.1080/15548627.2015.1089374
69. Terawaki S, Camosseto V, Prete F, Wenger T, Papadopoulos A, Rondeau $\mathrm{C}$, et al. RUN and FYVE domain-containing protein 4 enhances autophagy and lysosome tethering in response to Interleukin-4. J Cell Biol. (2015) 210:1133-52. doi: 10.1083/jcb.201501059

70. Xia F, Deng C, Jiang Y, Qu Y, Deng J, Cai Z, et al. IL4 (interleukin 4) induces autophagy in B cells leading to exacerbated asthma. Autophagy. (2018) 14:450-64. doi: 10.1080/15548627.2017.1421884

71. Dickinson JD, Alevy Y, Malvin NP, Patel KK, Gunsten SP, Holtzman MJ, et al. IL13 activates autophagy to regulate secretion in airway epithelial cells. Autophagy. (2016) 12:397-409. doi: 10.1080/15548627.2015.1056967

72. Van Grol J, Subauste C, Andrade RM, Fujinaga K, Nelson J, Subauste CS. HIV-1 inhibits autophagy in bystander macrophage/monocytic cells through Src-Akt and STAT3. PLoS ONE. (2010) 5:e11733. doi: 10.1371/journal.pone.0011733

73. Harris J, Hartman M, Roche C, Zeng SG, O'Shea A, Sharp FA, et al. Autophagy controls IL-1beta secretion by targeting pro-IL-1beta for degradation. J Biol Chem. (2011) 286:9587-97. doi: 10.1074/jbc.M110.202911

74. Saitoh T, Fujita N, Jang MH, Uematsu S, Yang BG, Satoh T, et al. Loss of the autophagy protein Atg16L1 enhances endotoxin-induced IL-1beta production. Nature. (2008) 456:264-8. doi: 10.1038/nature07383

75. Peral de Castro C, Jones SA, Ní Cheallaigh C, Hearnden CA, Williams L, Winter J, et al. Autophagy regulates IL-23 secretion and innate T cell responses through effects on IL-1 secretion. J Immunol. (2012) 189:4144-53. doi: 10.4049/jimmunol.1201946

76. Lee JP, Foote A, Fan H, Peral de Castro C, Lang T, Jones SA, et al. Loss of autophagy enhances MIF/macrophage migration inhibitory factor release by macrophages. Autophagy. (2016) 12:907-16. doi: 10.1080/15548627.2016.1164358

77. Yoon S, Woo SU, Kang JH, Kim K, Kwon MH, Park S, et al. STAT3 transcriptional factor activated by reactive oxygen species induces IL6 in starvation-induced autophagy of cancer cells. Autophagy. (2010) 6:1125-38. doi: 10.4161/auto.6.8.13547

78. Kiffin R, Christian C, Knecht E, Cuervo AM. Activation of chaperonemediated autophagy during oxidative stress. Mol Biol Cell. (2004) 15:482940. doi: 10.1091/mbc.e04-06-0477

79. Laplante M, Sabatini DM. mTOR signaling in growth control and disease. Cell. (2012) 149:274-93. doi: 10.1016/j.cell.2012.03.017

80. Kim J, Kundu M, Viollet B, Guan KL. AMPK and mTOR regulate autophagy through direct phosphorylation of Ulk1. Nat Cell Biol. (2011) 13:132-41. doi: $10.1038 / \mathrm{ncb} 2152$

81. Jang JE, Eom JI, Jeung HK, Cheong JW, Lee JY, Kim JS, et al. AMPKULK1-mediated autophagy confers resistance to BET inhibitor JQ1 in acute myeloid leukemia stem cells. Clin Cancer Res. (2017) 23:2781-94. doi: 10.1158/1078-0432.CCR-16-1903

82. Kim J, Kim YC, Fang C, Russell RC, Kim JH, Fan W, et al. Differential regulation of distinct Vps34 complexes by AMPK in nutrient stress and autophagy. Cell. (2013) 152:290-303. doi: 10.1016/j.cell.2012.12.016

83. Green DR, Levine B. To be or not to be? How selective autophagy and cell death govern cell fate. Cell. (2014) 157:65-75. doi: 10.1016/j.cell.2014.02.049

84. Li X, Wu XQ, Deng R, Li DD, Tang J, Chen WD, et al. CaMKII-mediated Beclin 1 phosphorylation regulates autophagy that promotes degradation of Id and neuroblastoma cell differentiation. Nat Commun. (2017) 8:1159. doi: 10.1038/s41467-017-01272-2

85. Sakamaki JI, Long JS, New M, Van Acker T, Tooze SA, Ryan KM. Emerging roles of transcriptional programs in autophagy regulation. Transcription. (2018) 9:131-6. doi: 10.1080/21541264.2017.1372045

86. Zhao J, Brault JJ, Schild A, Cao P, Sandri M, Schiaffino S, et al. FoxO3 coordinately activates protein degradation by the autophagic/lysosomal and proteasomal pathways in atrophying muscle cells. Cell Metab. (2007) 6:47283. doi: 10.1016/j.cmet.2007.11.004

87. Napolitano G, Ballabio A. TFEB at a glance. J Cell Sci. (2016) 129:2475-81. doi: $10.1242 /$ jcs.146365

88. Medina DL, Di Paola S, Peluso I, Armani A, De Stefani D, Venditti R, et al. Lysosomal calcium signalling regulates autophagy through calcineurin and TFEB. Nat Cell Biol. (2015) 17:288-99. doi: 10.1038/ncb3114

89. Bowman CJ, Ayer DE, Dynlacht BD. Foxk proteins repress the initiation of starvation-induced atrophy and autophagy programs. Nat Cell Biol. (2014) 16:1202-14. doi: 10.1038/ncb3062 
90. Baek SH, Kim KI. Epigenetic control of autophagy: nuclear events gain more attention. Mol Cell. (2017) 65:781-5. doi: 10.1016/j.molcel.2016.12.027

91. Füllgrabe J, Klionsky DJ, Joseph B. The return of the nucleus: transcriptional and epigenetic control of autophagy. Nat Rev Mol Cell Biol. (2014) 15:65-74. doi: $10.1038 / \mathrm{nrm} 3716$

92. Wei FZ, Cao Z, Wang X, Wang H, Cai MY, Li T, et al. Epigenetic regulation of autophagy by the methyltransferase EZH2 through an MTOR-dependent pathway. Autophagy. (2015) 11:2309-22. doi: 10.1080/15548627.2015.1117734

93. Sierra-Vargas MP, Guzman-Grenfell AM, Blanco-Jimenez S, SepulvedaSanchez JD, Bernabe-Cabanillas RM, Cardenas-Gonzalez B, et al. Airborne particulate matter $\mathrm{PM}_{2.5}$ from Mexico City affects the generation of reactive oxygen species by blood neutrophils from asthmatics: an in vitro approach. $J$ Occup Med Toxicol. (2009) 4:17. doi: 10.1186/1745-6673-4-17

94. Prieto-Parra L, Yohannessen K, Brea C, Vidal D, Ubilla CA, Ruiz-Rudolph P. Air pollution, $\mathrm{PM}_{2.5}$ composition, source factors, and respiratory symptoms in asthmatic and nonasthmatic children in Santiago, Chile. Environ Int. (2017) 101:190-200. doi: 10.1016/j.envint.2017.01.021

95. Bleck B, Tse DB, Curotto de Lafaille MA, Zhang F, Reibman J. Diesel exhaust particle-exposed human bronchial epithelial cells induce dendritic cell maturation and polarization via thymic stromal lymphopoietin. J Clin Immunol. (2008) 28:147-56. doi: 10.1007/s10875-007-9149-0

96. Bleck B, Tse DB, Gordon T, Ahsan MR, Reibman J. Diesel exhaust particle-treated human bronchial epithelial cells upregulate Jagged1 and OX40 ligand in myeloid dendritic cells via thymic stromal lymphopoietin. J Immunol. (2010) 185:6636-45. doi: 10.4049/jimmunol. 1000719

97. Nakamura Y, Miyata M, Ohba T, Ando T, Hatsushika K, Suenaga F, et al. Cigarette smoke extract induces thymic stromal lymphopoietin expression, leading to $\mathrm{T}(\mathrm{H}) 2$-type immune responses and airway inflammation. J Allergy Clin Immunol. (2008) 122:1208-14. doi: 10.1016/j.jaci.2008.09.022

98. Qu J, Do DC, Zhou Y, Luczak E, Mitzner W, Anderson ME, et al. Oxidized CaMKII promotes asthma through the activation of mast cells. JCI Insight. (2017) 2:e90139. doi: 10.1172/jci.insight.90139

99. Qu J, Li Y, Zhong W, Gao P, Hu C. Recent developments in the role of reactive oxygen species in allergic asthma. J Thorac Dis. (2017) 9:E32-43. doi: 10.21037/jtd.2017.01.05

100. Sanders PN, Koval OM, Jaffer OA, Prasad AM, Businga TR, Scott JA, et al. CaMKII is essential for the proasthmatic effects of oxidation. Sci Transl Med. (2013) 5:195ra97. doi: 10.1126/scitranslmed.3006135

101. Abdala-Valencia H, Earwood J, Bansal S, Jansen M, Babcock G, Garvy B, et al. Nonhematopoietic NADPH oxidase regulation of lung eosinophilia and airway hyperresponsiveness in experimentally induced asthma. Am J Physiol Lung Cell Mol Physiol. (2007) 292:L1111-25. doi: 10.1152/ajplung.00208.2006

102. Ban GY, Pham DL, Trinh TH, Lee SI, Suh DH, Yang EM, et al. Autophagy mechanisms in sputum and peripheral blood cells of patients with severe asthma: a new therapeutic target. Clin Exp Allergy. (2016) 46:48-59. doi: $10.1111 /$ cea.12585

103. Martin LJ, Gupta J, Jyothula SS, Butsch Kovacic M, Biagini Myers JM, Patterson TL, et al. Functional variant in the autophagy-related 5 gene promotor is associated with childhood asthma. PLoS ONE. (2012) 7:e33454. doi: 10.1371/journal.pone.0033454

104. Chen ZH, Wu YF, Wang PL, Wu YP, Li ZY, Zhao Y, et al. Autophagy is essential for ultrafine particle-induced inflammation and mucus hyperproduction in airway epithelium. Autophagy. (2016) 12:297-311. doi: 10.1080/15548627.2015.1124224

105. Li Y, Qian W, Wang D, Meng Y, Wang X, Chen Y, et al. Resveratrol relieves particulate matter (mean diameter $<2.5$ mum)-induced oxidative injury of lung cells through attenuation of autophagy deregulation. J Appl Toxicol JAT. (2018) 38:1251-61. doi: 10.1002/jat.3636

106. Long F, Jiang H, Yi H, Su L, Sun J. Particulate matter 2.5 induced bronchial epithelial cell injury via activation of 5'-adenosine monophosphate-activated protein kinase-mediated autophagy. J Cell Biochem. (2019) 120:3294-305. doi: $10.1002 /$ jcb. 27597

107. Fu Q, Lyu D, Zhang L, Qin Z, Tang Q, Yin H, et al. Airborne particulate matter $\left(\mathrm{PM}_{2.5}\right)$ triggers autophagy in human corneal epithelial cell line. Environ Pollut. (2017) 227:314-22. doi: 10.1016/j.envpol.2017.04.078
108. Bush RK, Prochnau JJ. Alternaria-induced asthma. J Allergy Clin Immunol. (2004) 113:227-34. doi: 10.1016/j.jaci.2003.11.023

109. Murai H, Qi H, Choudhury B, Wild J, Dharajiya N, Vaidya S, et al. Alternariainduced release of IL-18 from damaged airway epithelial cells: an NF-kappaB dependent mechanism of Th2 differentiation? PLoS ONE. (2012) 7:e30280. doi: 10.1371/journal.pone.0030280

110. Abdel Fattah E, Bhattacharya A, Herron A, Safdar Z, Eissa NT. Critical role for IL-18 in spontaneous lung inflammation caused by autophagy deficiency. J Immunol. (2015) 194:5407-16. doi: 10.4049/jimmunol.1402277

111. Zhang YDD, Zhang X, Wang J, Anderson M, Gao P. Autophagy participates in cockroach allergen-induced lung inflammation through ROS and oxidized CaMKII. J Allergy Clin Immunol. (2019) 143:AB218. doi: 10.1016/j.jaci.2018.12.665

112. Suzuki Y, Maazi H, Sankaranarayanan I, Lam J, Khoo B, Soroosh P, et al. Lack of autophagy induces steroid-resistant airway inflammation. J Allergy Clin Immunol. (2016) 137:1382-9.e9. doi: 10.1016/j.jaci.2015.09.033

113. Wang SB, Wu YF, Chen ZH, Li W, Shen HH. [Airway epithelial ATG5 suppresses asthmatic inflammation in mice]. Zhonghua Jie He He Hu Xi Za Zhi. (2018) 41:873-7. doi: 10.3760/cma.j.issn.1001-0939.2018.11.009

114. Inoue $\mathrm{D}$, Kubo $\mathrm{H}$, Taguchi $\mathrm{K}$, Suzuki $\mathrm{T}$, Komatsu M, Motohashi $\mathrm{H}$, et al. Inducible disruption of autophagy in the lung causes airway hyper-responsiveness. Biochem Biophys Res Commun. (2011) 405:13-8. doi: 10.1016/j.bbrc.2010.12.092

115. Pu Q, Gan C, Li R, Li Y, Tan S, Li X, et al. Atg7 deficiency intensifies inflammasome activation and pyroptosis in pseudomonas sepsis. J Immunol. (2017) 198:3205-13. doi: 10.4049/jimmunol.1601196

116. Guo L, Stripay JL, Zhang X, Collage RD, Hulver M, Carchman $\mathrm{EH}$, et al. CaMKIalpha regulates AMP kinase-dependent, TORC1 -independent autophagy during lipopolysaccharide-induced acute lung neutrophilic inflammation. J Immunol. (2013) 190:3620-8. doi: 10.4049/jimmunol.1102975

117. Jessop F, Hamilton RF, Rhoderick JF, Shaw PK, Holian A. Autophagy deficiency in macrophages enhances NLRP3 inflammasome activity and chronic lung disease following silica exposure. Toxicol Appl Pharmacol. (2016) 309:101-10. doi: 10.1016/j.taap.2016.08.029

118. Cheng Z, Wang X, Dai L, Jia L, Jing X, Liu Y, et al. Suppression of microRNA384 enhances autophagy of airway smooth muscle cells in asthmatic mouse. Oncotarget. (2017) 8:67933-41. doi: 10.18632/oncotarget.18913

119. Ghavami S, Mutawe MM, Schaafsma D, Yeganeh B, Unruh H, Klonisch T, et al. Geranylgeranyl transferase 1 modulates autophagy and apoptosis in human airway smooth muscle. Am J Physiol Lung Cell Mol Physiol. (2012) 302:L420-8. doi: 10.1152/ajplung.00312.2011

120. Pan S, Sharma P, Shah SD, Deshpande DA. Bitter taste receptor agonists alter mitochondrial function and induce autophagy in airway smooth muscle cells. Am J Physiol Lung Cell Mol Physiol. (2017) 313:L154-65. doi: 10.1152/ajplung.00106.2017

121. Neill T, Schaefer L, Iozzo RV. Instructive roles of extracellular matrix on autophagy. Am J Pathol. (2014) 184:2146-53. doi: 10.1016/j.ajpath.2014.05.010

122. Poon AH, Choy DF, Chouiali F, Ramakrishnan RK, Mahboub B, Audusseau S, et al. Increased autophagy-related 5 gene expression is associated with collagen expression in the airways of refractory asthmatics. Front Immunol. (2017) 8:355. doi: 10.3389/fimmu.2017. 00355

123. Liu T, Liu Y, Miller M, Cao L, Zhao J, Wu J, et al. Autophagy plays a role in FSTL1-induced epithelial mesenchymal transition and airway remodeling in asthma. Am J Physiol Lung Cell Mol Physiol. (2017) 313:L2740. doi: 10.1152/ajplung.00510.2016

124. Kota A, Deshpande DA, Haghi M, Oliver B, Sharma P. Autophagy and airway fibrosis: is there a link? F1000Res. (2017) 6:409. doi: 10.12688/f1000research.11236.1

125. Ghavami S, Yeganeh B, Serebrin A, et al. Autophagy regulates Tgf-betal induced fibrosis in human airway smooth muscle cells. Proc Am Thorac Soc. (2011) 183:A2110. doi: 10.1164/ajrccm-conference.2011.183.1_MeetingAbstracts.A2110

126. Aguilera-Aguirre L, Bacsi A, Saavedra-Molina A, Kurosky A, Sur S, Boldogh I. Mitochondrial dysfunction increases allergic airway inflammation. J Immunol. (2009) 183:5379-87. doi: 10.4049/jimmunol.0900228 
127. Iyer D, Mishra N, Agrawal A. Mitochondrial function in allergic disease. Curr Allergy Asthma Rep. (2017) 17:29. doi: 10.1007/s11882-017-0695-0

128. Pattnaik B, Bodas M, Bhatraju NK, Ahmad T, Pant R, Guleria R, et al. IL-4 promotes asymmetric dimethylarginine accumulation, oxo-nitrative stress, and hypoxic response-induced mitochondrial loss in airway epithelial cells. $J$ Allergy Clin Immunol. (2016) 138:130-41.e9. doi: 10.1016/j.jaci.2015.11.036

129. Reddy PH. Mitochondrial dysfunction and oxidative stress in asthma: implications for mitochondria-targeted antioxidant therapeutics. Pharmaceuticals. (2011) 4:429-56. doi: 10.3390/ph4030429

130. Wang A, Keita ÅV, Phan V, McKay CM, Schoultz I, Lee J, et al. Targeting mitochondria-derived reactive oxygen species to reduce epithelial barrier dysfunction and colitis. Am J Pathol. (2014) 184:2516-27. doi: 10.1016/j.ajpath.2014.05.019

131. Li R, Kou X, Geng H, Xie J, Yang Z, Zhang Y, et al. Effect of ambient PM(2.5) on lung mitochondrial damage and fusion/fission gene expression in rats. Chem Res Toxicol. (2015) 28:408-18. doi: 10.1021/tx5003723

132. Qiu YN, Wang GH, Zhou F, Hao JJ, Tian L, Guan LF, et al. $\mathrm{PM}_{2.5}$ induces liver fibrosis via triggering ROS-mediated mitophagy. Ecotoxicol Environ Saf. (2019) 167:178-87. doi: 10.1016/j.ecoenv.2018.08.050

133. Stevens JF, Maier CS. Acrolein: sources, metabolism, and biomolecular interactions relevant to human health and disease. Mol Nutr Food Res. (2008) 52:7-25. doi: 10.1002/mnfr.200700412

134. Wang HT, Lin JH, Yang $\mathrm{CH}$, Haung $\mathrm{CH}$, Weng $\mathrm{CW}$, Maan-Yuh Lin A, et al. Acrolein induces mtDNA damages, mitochondrial fission and mitophagy in human lung cells. Oncotarget. (2017) 8:70406-21. doi: 10.18632/oncotarget.19710

135. Sliter DA, Martinez J, Hao L, Chen X, Sun N, Fischer TD, et al. Parkin and PINK1 mitigate STING-induced inflammation. Nature. (2018) 561:258-62. doi: 10.1038/s41586-018-0448-9

136. Youle RJ, Narendra DP. Mechanisms of mitophagy. Nat Rev Mol Cell Biol. (2011) 12:9-14. doi: 10.1038/nrm3028

137. Palikaras K, Lionaki E, Tavernarakis N. Mechanisms of mitophagy in cellular homeostasis, physiology and pathology. Nat Cell Biol. (2018) 20:1013-22. doi: 10.1038/s41556-018-0176-2

138. Jin SM, Lazarou M, Wang C, Kane LA, Narendra DP, Youle RJ. Mitochondrial membrane potential regulates PINK1 import and proteolytic destabilization by PARL. J Cell Biol. (2010) 191:933-42. doi: $10.1083 /$ jcb.201008084

139. Pickles S, Vigié P, Youle RJ. Mitophagy and quality control mechanisms in mitochondrial maintenance. Curr Biol CB. (2018) 28:R170-85. doi: 10.1016/j.cub.2018.01.004

140. Lazarou M, Sliter DA, Kane LA, Sarraf SA, Wang C, Burman JL, et al. The ubiquitin kinase PINK1 recruits autophagy receptors to induce mitophagy. Nature. (2015) 524:309-14. doi: 10.1038/nature14893

141. Moore AS, Holzbaur EL. Dynamic recruitment and activation of ALS-associated TBK1 with its target optineurin are required for efficient mitophagy. Proc Natl Acad Sci USA. (2016) 113:E3349-58. doi: 10.1073/pnas.1523810113

142. Richter B, Sliter DA, Herhaus L, Stolz A, Wang C, Beli P, et al. Phosphorylation of OPTN by TBK1 enhances its binding to Ub chains and promotes selective autophagy of damaged mitochondria. Proc Natl Acad Sci USA. (2016) 113:4039-44. doi: 10.1073/pnas.1523926113

143. Shen Z, Li Y, Gasparski AN, Abeliovich H, Greenberg ML. Cardiolipin regulates mitophagy through the protein kinase $\mathrm{C}$ pathway. J Biol Chem. (2017) 292:2916-23. doi: 10.1074/jbc.M116.753574

144. Wei Y, Chiang WC, Sumpter R Jr., Mishra P, Levine B. Prohibitin 2 is an inner mitochondrial membrane mitophagy receptor. Cell. (2017) 168:224-38.e10. doi: 10.1016/j.cell.2016.11.042

145. Tsubouchi K, Araya J, Kuwano K. PINK1-PARK2-mediated mitophagy in COPD and IPF pathogeneses. Inflamm Regen. (2018) 38:18. doi: 10.1186/s41232-018-0077-6

146. Bueno M, Lai YC, Romero Y, Brands J, St Croix CM, Kamga C, et al. PINK1 deficiency impairs mitochondrial homeostasis and promotes lung fibrosis. $J$ Clin Invest. (2015) 125:521-38. doi: 10.1172/JCI74942

147. Kobayashi K, Araya J, Minagawa S, Hara H, Saito N, Kadota T, et al. Involvement of PARK2-mediated mitophagy in idiopathic pulmonary fibrosis pathogenesis. J Immunol. (2016) 197:504-16. doi: 10.4049/jimmunol.1600265
148. Sosulski ML, Gongora R, Danchuk S, Dong C, Luo F, Sanchez CG. Deregulation of selective autophagy during aging and pulmonary fibrosis: the role of TGF $\beta 1$. Aging Cell. (2015) 14:774-83. doi: 10.1111/acel.12357

149. Patel AS, Song JW, Chu SG, Mizumura K, Osorio JC, Shi Y, et al. Epithelial cell mitochondrial dysfunction and PINK1 are induced by transforming growth factor-betal in pulmonary fibrosis. PLoS ONE. (2015) 10:e0121246. doi: 10.1371/journal.pone.0121246

150. Fan P, Xie XH, Chen CH, Peng X, Zhang P, Yang C, et al. Molecular regulation mechanisms and interactions between reactive oxygen species and mitophagy. DNA Cell Biol. (2019) 38:10-22. doi: 10.1089/dna.2018.4348

151. Wiley CD, Velarde MC, Lecot P, Liu S, Sarnoski EA, Freund A, et al. Mitochondrial dysfunction induces senescence with a distinct secretory phenotype. Cell Metab. (2016) 23:303-14. doi: 10.1016/j.cmet.2015.11.011

152. Schuliga M, Pechkovsky DV, Read J, Waters DW, Blokland KEC, Reid AT, et al. Mitochondrial dysfunction contributes to the senescent phenotype of IPF lung fibroblasts. J Cell Mol Med. (2018) 22:5847-61. doi: $10.1111 /$ jcmm. 13855

153. Parikh P, Wicher S, Khandalavala K, Pabelick CM, Britt RD Jr., Prakash YS. Cellular senescence in the lung across the age spectrum. Am J Physiol Lung Cell Mol Physiol. (2019) 316:L826-42. doi: 10.1152/ajplung.00424.2018

154. Hadj Salem I, Dubé J, Boulet LP, Chakir J. Telomere shortening correlates with accelerated replicative senescence of bronchial fibroblasts in asthma. Clin Exp Allergy. (2015) 45:1713-5. doi: 10.1111/cea.12611

155. Belsky DW, Shalev I, Sears MR, Hancox RJ, Lee Harrington H, Houts $\mathrm{R}$, et al. Is chronic asthma associated with shorter leukocyte telomere length at midlife? Am J Respir Crit Care Med. (2014) 190:384-91. doi: 10.1164/rccm.201402-0370OC

156. Sidler C, Kovalchuk O, Kovalchuk I. Epigenetic regulation of cellular senescence and aging. Front Genet. (2017) 8:138. doi: 10.3389/fgene.2017.00138

157. Pereira BI, Devine OP, Vukmanovic-Stejic M, Chambers ES, Subramanian $\mathrm{P}$, Patel N, et al. Senescent cells evade immune clearance via HLA-Emediated NK and CD8(+) T cell inhibition. Nat Commun. (2019) 10:2387. doi: 10.1038/s41467-019-10335-5

158. Campisi J, d'Adda di Fagagna F. Cellular senescence: when bad things happen to good cells. Nat Rev Mol Cell Biol. (2007) 8:729-40. doi: 10.1038/ nrm2233

159. Krtolica A, Parrinello S, Lockett S, Desprez PY, Campisi J. Senescent fibroblasts promote epithelial cell growth and tumorigenesis: a link between cancer and aging. Proc Natl Acad Sci USA. (2001) 98:12072-7. doi: $10.1073 /$ pnas. 211053698

160. Birch J, Barnes PJ, Passos JF. Mitochondria, telomeres and cell senescence: implications for lung ageing and disease. Pharmacol Ther. (2018) 183:34-49. doi: 10.1016/j.pharmthera.2017.10.005

161. Li C, Chai Y, Wang L, Gao B, Chen H, Gao P, et al. Programmed cell senescence in skeleton during late puberty. Nat Commun. (2017) 8:1312. doi: 10.1038/s41467-017-01509-0

162. Childs BG, Baker DJ, Wijshake T, Conover CA, Campisi J, van Deursen JM. Senescent intimal foam cells are deleterious at all stages of atherosclerosis. Science. (2016) 354:472-7. doi: 10.1126/science.aaf6659

163. Jeon OH, Kim C, Laberge RM, Demaria M, Rathod S, Vasserot AP, et al. Local clearance of senescent cells attenuates the development of post-traumatic osteoarthritis and creates a pro-regenerative environment. Nat Med. (2017) 23:775. doi: $10.1038 / \mathrm{nm} .4324$

164. van Deursen JM. The role of senescent cells in ageing. Nature. (2014) 509:439-46. doi: 10.1038/nature13193

165. Lee S, Schmitt CA. The dynamic nature of senescence in cancer. Nat Cell Biol. (2019) 21:94-101. doi: 10.1038/s41556-018-0249-2

166. Martínez-Zamudio RI, Robinson L, Roux PF, Bischof O. SnapShot: cellular senescence pathways. Cell. (2017) 170:816-e1. doi: 10.1016/j.cell.2017. 07.049

167. Hardie DG, Ross FA, Hawley SA. AMPK: a nutrient and energy sensor that maintains energy homeostasis. Nat Rev Mol Cell Biol. (2012) 13:251-62. doi: 10.1038/nrm3311

168. Ogrodnik M, Zhu Y, Langhi LGP, Tchkonia T, Krüger P, Fielder $\mathrm{E}$, et al. Obesity-induced cellular senescence drives anxiety and impairs neurogenesis. Cell Metab. (2019) 29:1061-77.e8. doi: $10.1016 /$ j.cmet.2018.12.008 
169. Burton DGA, Stolzing A. Cellular senescence: immunosurveillance and future immunotherapy. Ageing Res Rev. (2018) 43:17-25. doi: 10.1016/j.arr.2018.02.001

170. Krizhanovsky V, Yon M, Dickins RA, Hearn S, Simon J, Miething C, et al. Senescence of activated stellate cells limits liver fibrosis. Cell. (2008) 134:65767. doi: 10.1016/j.cell.2008.06.049

171. Sagiv A, Burton DG, Moshayev Z, Vadai E, Wensveen F, Ben-Dor S, et al. NKG2D ligands mediate immunosurveillance of senescent cells. Aging. (2016) 8:328-44. doi: 10.18632/aging.100897

172. Iannello A, Thompson TW, Ardolino M, Lowe SW, Raulet DH. p53dependent chemokine production by senescent tumor cells supports NKG2D-dependent tumor elimination by natural killer cells. J Exp Med. (2013) 210:2057-69. doi: 10.1084/jem.20130783

173. Kang JY, Lee SY, Rhee CK, Kim SJ, Kwon SS, Kim YK. Effect of aging on airway remodeling and muscarinic receptors in a murine acute asthma model. Clin Interv Aging. (2013) 8:1393-403. doi: 10.2147/CIA.S50496

174. Amsellem V, Gary-Bobo G, Marcos E, Maitre B, Chaar V, Validire P, et al. Telomere dysfunction causes sustained inflammation in chronic obstructive pulmonary disease. Am J Respir Crit Care Med. (2011) 184:1358-66. doi: 10.1164/rccm.201105-0802OC

175. Schafer MJ, White TA, Iijima K, Haak AJ, Ligresti G, Atkinson EJ, et al. Cellular senescence mediates fibrotic pulmonary disease. Nat Commun. (2017) 8:14532. doi: 10.1038/ncomms 14532

176. Fedorov IA, Wilson SJ, Davies DE, Holgate ST. Epithelial stress and structural remodelling in childhood asthma. Thorax. (2005) 60:389-94. doi: $10.1136 /$ thx.2004.030262

177. Jedrychowski WA, Perera FP, Maugeri U, Mroz E, KlimaszewskaRembiasz M, Flak E, et al. Effect of prenatal exposure to fine particulate matter on ventilatory lung function of preschool children of nonsmoking mothers. Paediatr Perinat Epidemiol. (2010) 24:492-501. doi: 10.1111/j.1365-3016.2010.01136.x

178. Martens DS, Cox B, Janssen BG, Clemente DBP, Gasparrini A, Vanpoucke C, et al. Prenatal air pollution and newborns' predisposition to accelerated biological aging. JAMA Pediatr. (2017) 171:1160-7. doi: 10.1001/jamapediatrics.2017.3024

179. Mahemuti L, Chen Q, Coughlan MC, Qiao C, Chepelev NL, Florian $\mathrm{M}$, et al. Bisphenol A induces DSB-ATM-p53 signaling leading to cell cycle arrest, senescence, autophagy, stress response, and estrogen release in human fetal lung fibroblasts. Arch Toxicol. (2018) 92:1453-69. doi: 10.1007/s00204-017-2150-3

180. Jiang C, Liu G, Luckhardt T, Antony V, Zhou Y, Carter AB, et al. Serpine 1 induces alveolar type II cell senescence through activating p53p21-Rb pathway in fibrotic lung disease. Aging Cell. (2017) 16:1114-24. doi: 10.1111/acel.12643

181. Rana T, Jiang C, Liu G, Miyata T, Antony V, Thannickal VJ, et al. PAI-1 regulation of TGF-beta1-induced ATII Cell senescence, SASP secretion, and SASP-mediated Activation of Alveolar Macrophages. Am J Respir Cell Mol Biol. (2019). doi: 10.1165/rcmb.2019-0071OC. [Epub ahead of print].

182. Rodier F, Coppé JP, Patil CK, Hoeijmakers WA, Muñoz DP, Raza SR, et al. Persistent DNA damage signalling triggers senescence-associated inflammatory cytokine secretion. Nat Cell Biol. (2009) 11:973-9. doi: $10.1038 /$ ncb1909

183. Loubaki L, Semlali A, Boisvert M, Jacques E, Plante S, Aoudjit F, et al. Crosstalk between $\mathrm{T}$ cells and bronchial fibroblasts obtained from asthmatic subjects involves CD40L/alpha 5 beta 1 interaction. Mol Immunol. (2010) 47:2112-8. doi: 10.1016/j.molimm.2010.03.011

184. Roca R, Kypta RM, Vivanco Md. Loss of p16INK4a results in increased glucocorticoid receptor activity during fibrosarcoma development. Proc Natl Acad Sci USA. (2003) 100:3113-8. doi: 10.1073/pnas.0634 912100

185. Hodge G, Jersmann H, Tran HB, Holmes M, Reynolds PN, Hodge S. Lymphocyte senescence in COPD is associated with loss of glucocorticoid receptor expression by pro-inflammatory/cytotoxic lymphocytes. Respir Res. (2015) 16:2. doi: 10.1186/s12931-015-0287-2

186. KleinJan A. Airway inflammation in asthma: key players beyond the Th2 pathway. Curr Opin Pulm Med. (2016) 22:46-52. doi: 10.1097/MCP.0000000000000224

187. Huang J, Li Z, Yao X, Li Y, Reng X, Li J, et al. Altered Th1/Th2 commitment contributes to lung senescence in CXCR3-deficient mice. Exp Gerontol. (2013) 48:717-26. doi: 10.1016/j.exger.2013.04.001

188. Kuwano K, Araya J, Hara H, Minagawa S, Takasaka N, Ito S, et al. Cellular senescence and autophagy in the pathogenesis of chronic obstructive pulmonary disease (COPD) and idiopathic pulmonary fibrosis (IPF). Respir Investig. (2016) 54:397-406. doi: 10.1016/j.resinv.2016.03.010

189. Rajendran P, Alzahrani AM, Hanieh HN, Kumar SA, Ben Ammar R, Rengarajan T, et al. Autophagy and senescence: a new insight in selected human diseases. J Cell Physiol. (2019) 234:21485-92. doi: 10.1002/jcp.28895

190. Narita M, Young AR, Arakawa S, Samarajiwa SA, Nakashima T, Yoshida $S$, et al. Spatial coupling of mTOR and autophagy augments secretory phenotypes. Science. (2011) 332:966-70. doi: 10.1126/science.1205407

191. Suzuki T, Nakagawa M, Yoshikawa A, Sasagawa N, Yoshimori T, Ohsumi $\mathrm{Y}$, et al. The first molecular evidence that autophagy relates rimmed vacuole formation in chloroquine myopathy. J Biochem. (2002) 131:647-51. doi: 10.1093/oxfordjournals.jbchem.a003147

192. Werner G, Hagenmaier H, Drautz H, Baumgartner A, Zähner H. Metabolic products of microorganisms. 224. Bafilomycins, a new group of macrolide antibiotics. Production, isolation, chemical structure and biological activity. J Antibiot. (1984) 37:110-7. doi: 10.7164/antibiotics.37.110

193. Hardie DG. AMPK: a target for drugs and natural products with effects on both diabetes and cancer. Diabetes. (2013) 62:2164-72. doi: $10.2337 / \mathrm{db} 13-0368$

194. Kim J, Yang G, Kim Y, Kim J, Ha J. AMPK activators: mechanisms of action and physiological activities. Exp Mol Med. (2016) 48:e224. doi: $10.1038 / \mathrm{emm} .2016 .16$

195. Mora AL, Rojas M, Pardo A, Selman M. Emerging therapies for idiopathic pulmonary fibrosis, a progressive age-related disease. Nat Rev Drug Discov. (2017) 16:755-72. doi: 10.1038/nrd.2017.170

196. Barnes PJ. Senescence in COPD and its comorbidities. Annu Rev Physiol. (2017) 79:517-39. doi: 10.1146/annurev-physiol-022516-034314

197. Zhang Y, Jing Y, Qiao J, Luan B, Wang X, Wang L, et al. Activation of the mTOR signaling pathway is required for asthma onset. Sci Rep. (2017) 7:4532. doi: 10.1038/s41598-017-04826-y

198. Herranz N, Gallage S, Mellone M, Wuestefeld T, Klotz S, Hanley CJ, et al. mTOR regulates MAPKAPK2 translation to control the senescence-associated secretory phenotype. Nat Cell Biol. (2015) 17:1205-17. doi: $10.1038 /$ ncb3225

199. Chang J, Wang Y, Shao L, Laberge RM, Demaria M, Campisi J, et al. Clearance of senescent cells by ABT263 rejuvenates aged hematopoietic stem cells in mice. Nat Med. (2016) 22:78-83. doi: 10.1038/nm.4010

200. Baker DJ, Wijshake T, Tchkonia T, LeBrasseur NK, Childs BG, van de Sluis B, et al. Clearance of p16Ink4a-positive senescent cells delays ageing-associated disorders. Nature. (2011) 479:232-6. doi: 10.1038/nature10600

Conflict of Interest: The authors declare that the research was conducted in the absence of any commercial or financial relationships that could be construed as a potential conflict of interest.

Copyright (c) 2019 Sachdeva, Do, Zhang, Hu, Chen and Gao. This is an open-access article distributed under the terms of the Creative Commons Attribution License (CC $B Y)$. The use, distribution or reproduction in other forums is permitted, provided the original author(s) and the copyright owner(s) are credited and that the original publication in this journal is cited, in accordance with accepted academic practice. No use, distribution or reproduction is permitted which does not comply with these terms. 